\title{
Working
}

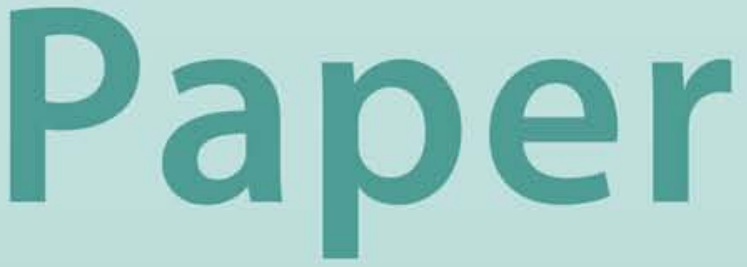




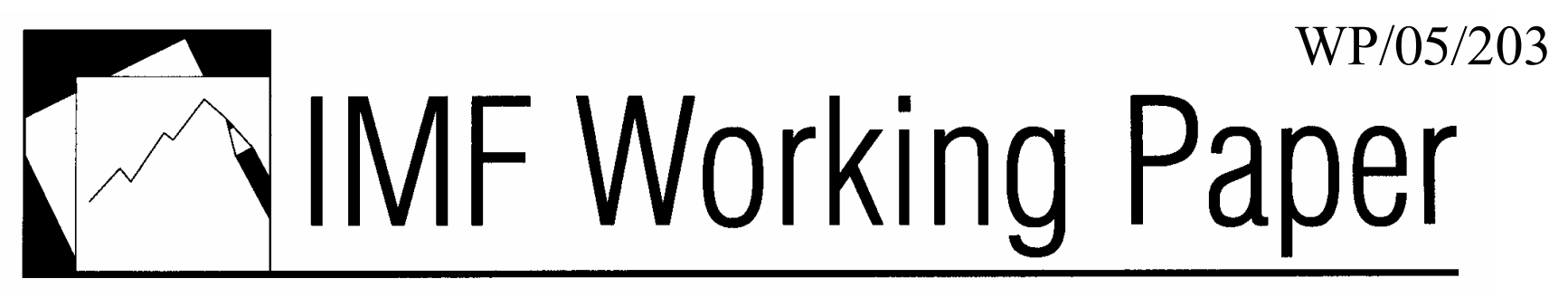

Revenue Administration Reform in
Middle Eastern Countries, 1994-2004

William Crandall and Jean-Paul Bodin 


\title{
IMF Working Paper
}

Fiscal Affairs Department

\section{Revenue Administration Reform in Middle Eastern Countries, 1994-2004}

\author{
Prepared by William Crandall and Jean-Paul Bodin ${ }^{1}$
}

October 2005

\begin{abstract}
This Working Paper should not be reported as representing the views of the IMF. The views expressed in this Working Paper are those of the author(s) and do not necessarily represent those of the IMF or IMF policy. Working Papers describe research in progress by the author(s) and are published to elicit comments and to further debate.

The paper provides an overview of revenue administration reforms implemented in Middle Eastern and North African countries over the past decade with IMF assistance. Although reforming tax and customs administration is neither quick nor simple, several countries in the region have embarked on comprehensive programs of reforms to modernize their revenue administration, and encouraging progress has been achieved. Experience shows that there are many challenges to be faced and that critical requirements need to be met, including political commitment, strong leadership, willingness to abandon ineffective practices; and establishment of reform projects with clear mandates, agreed objectives, and realistic timeframes.
\end{abstract}

JEL Classification Numbers: E62

Keywords: Revenue, tax, customs administration

Author(s) E-Mail Address: williamcrandall@canoemail.com and jbodin@imf.org

\footnotetext{
1 Jean-Paul Bodin is a division chief in the Revenue Administration Division 1 of the IMF's Fiscal Affairs Department (FAD). William Crandall is a senior panel expert (FAD). The authors are grateful to Mr. Abdel Rahman for his support and advice. They are also thankful to Michael Keen and Mario Mansur (from FAD Tax Policy Division), Olivier Benon (from the Middle East Technical Assistance Center-METAC), Gene Leon (from the Middle East and Central Asia Department), and David Kloeden, Maureen Kidd, and Egil Martinsen (from FADR1) for their comments. The authors alone are responsible for any errors.
} 
Introduction $\underline{3}$

I. Background on the Middle Eastern Region..............................................................

II. Revenue Administration Reform and Policy Issues.................................................... 9

III. Reform Effort Over the Past Ten Years in the Middle East ........................................14

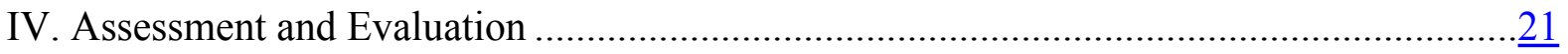

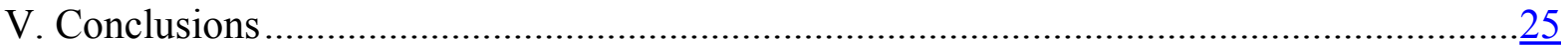

Appendices

I. Features of Tax Administration in Selected Middle Eastern Countries .............................26

II. Features of Customs Administration in Selected Middle Eastern Countries ......................28

III. Selected Case Studies (Egypt, Jordan, Lebanon, Morocco, Pakistan, and Sudan)............. $\underline{30}$

Boxes

1. Key Design Features that Are Conducive to Value-Added Tax Revenue Performance ....... 1

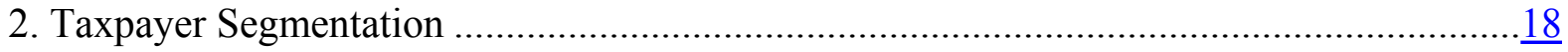

Tables

1. Non-Oil Revenue Structure (Central Government)—Regional Average, 1997-2001 ......... 4

2. Revenues as a Percentage of GDP in Selected Countries, 1990 vs. 2000 ......................... $\frac{5}{6}$

3. Trade Taxes as a Share of Total Tax Revenue, 1980-98 .................................................

4. Value-Added Tax Features by Region, November 2000 ..................................................

5. Characteristics of the Value-Added Tax in Middle Eastern Countries, 2004...................... 8

6. Features of Tax Administration in Selected Countries, Early 1990s vs. Today ..................27

7. Features of Customs Administration in Selected Countries, Early 1990s vs. Today ...........29

8. Egypt: Consolidated Revenue Collection, 2001/02-2004/05 …......................................

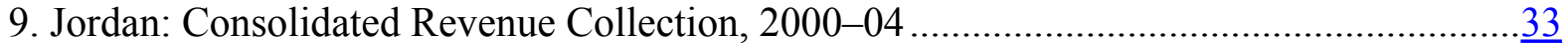

10. Lebanon: Consolidated Revenue Collection, 2002-04............................................. $\frac{35}{38}$

11. Morocco: Consolidated Revenue Collection, 1999-2003 ............................................. $\underline{38}$

12. Pakistan: Federal Revenue Collection, 1999/00-2003/04 .......................................... $\frac{41}{44}$

13. Sudan: Consolidated Revenue Collection, 2000-04.................................................44 


\section{Introduction}

The purpose of this paper is to review revenue administration reforms implemented over the past ten years in selected Middle Eastern and North African countries, including Afghanistan, Algeria, Egypt, the Islamic Republic of Iran, Jordan, Lebanon, Mauritania, Morocco, Pakistan, Saudi Arabia, Sudan, Tunisia, and Yemen. These countries have been selected from among those where IMF Fiscal Affairs Department (FAD) technical assistance (TA) in tax and customs administration has been requested in the past ten years. It is important to mention that, in recent months, other countries, including Libya and Syria, have also requested FAD TA to support implementation of their revenue administration reforms.

In the Middle Eastern and North African countries, ${ }^{2}$ an important goal is to improve the structure and administration of the tax and customs systems to enhance efficiency and (non-oil) revenue mobilization. The provision of TA in these areas is the responsibility of the FAD Revenue Administration (R1) and Tax Policy (TP) divisions. ${ }^{3}$

This paper provides a discussion of: (1) key background features and revenue performance in the Middle Eastern region; (2) revenue administration reform and policy issues; (3) revenue administration reform and progress in the region over the past ten years; and (4) an assessment of the reforms that have been implemented. ${ }^{4}$

\footnotetext{
2 These will be identified as "Middle Eastern" countries in the remainder of this paper.

${ }^{3}$ The authors are grateful to Abdel Rahman for his support and advice. They are also thankful to Mario Mansur (from FAD TP), Olivier Benon (from the Middle East Technical Assistance Center-METAC), and David Kloeden, Maureen Kidd, and Egil Martinsen (from FAD R1) for their comments.

${ }^{4}$ A presentation of the preliminary conclusions of this paper was made during the Conference on Fiscal Reforms in Middle Eastern Countries that was organized in Beirut on May 18-19, 2004.
} 


\section{BACKGROUND ON THE MidDle EASTERN REGION}

\section{Revenue structure and interregional comparisons}

Despite inherent difficulties in regional comparisons, ${ }^{5}$ it is useful to examine Middle Eastern countries' tax revenues in the light of performance in other regions. Table 1 presents a regional comparison for the period 1997-2001. It is clear from the data presented that tax revenues for the Middle East over this period are low by worldwide standards, reflecting a variety of factors but certainly contributing to a desire on the part of many governments to make revenue administration reform a priority.

Table 1. Non-Oil Revenue Structure (Central Government)—Regional Average, 1997-20016 (In percent of GDP)

\begin{tabular}{lrrrrrrr}
\hline & OECD & $\begin{array}{c}\text { Central } \\
\text { Europe }\end{array}$ & $\begin{array}{c}\text { Russia and } \\
\text { CIS }\end{array}$ & Africa & $\begin{array}{c}\text { Latin } \\
\text { America }\end{array}$ & $\begin{array}{c}\text { Asia } \\
\text { Middle } \\
\text { East }\end{array}$ \\
\hline Tax revenue & 29.4 & 28.4 & 16.8 & 17.4 & 17.2 & 13.7 & 13.8 \\
$\quad$ Direct taxes & 9.8 & 5.5 & 2.1 & 4.8 & 3.8 & 4.4 & 4.9 \\
Social contributions & 8.3 & 9.4 & 4.8 & 0.5 & 2.2 & 0.3 & 0.8 \\
Indirect taxes & 10.0 & 11.8 & 8.2 & 4.8 & 7.2 & 5.3 & 3.9 \\
Customs duties & 0.6 & 1.2 & 1.3 & 6.8 & 3.1 & 3.1 & 3.1 \\
\hline
\end{tabular}

Source: IMF.

In terms of particular countries in the region, Table 2 examines revenues for selected Middle Eastern countries over a ten-year period, comparing 1990 with 2000. Focusing on tax revenues, there are improvements in Lebanon and Tunisia, and to some extent in Jordan and Morocco. However, in other countries, tax revenues as a percentage of GDP have declined (including in Algeria, Egypt, Mauritania, and Yemen). Interpretation of these variations would need to take into consideration a variety of factors ranging from changes in the tax system (including in the level of tax rates and customs tariffs, and the scope of exemptions) to modifications in the political, social, and economic circumstances. Moreover, in the five years since 2000 , there have been many further changes, particularly for those countries that introduced the value-added tax (VAT) after 2000.

As a further general comment, while trade taxes (excluding VAT on imports) have generally decreased, they still remain relatively high in the Middle East compared with the rest of the world (see Table 3 on trade taxes as a share of total tax revenue). Only Africa is higher.

\footnotetext{
${ }^{5}$ These would include timing, the noncomparability of data, differences in classification of taxes, and the like.

${ }^{6}$ Unweighted. For each revenue classification, only countries for which data are available are included.
} 
Combined with the spread of the VAT (see below), this has implications for customs administration reform because the revenue collection role of customs in the Middle East will continue to be critical for the foreseeable future.

\begin{tabular}{|c|c|c|c|c|c|c|c|c|c|c|c|c|}
\hline & \multicolumn{2}{|c|}{ Algeria } & \multicolumn{2}{|c|}{ Egypt } & \multicolumn{2}{|c|}{ Iran } & \multicolumn{2}{|c|}{ Jordan } & \multicolumn{2}{|c|}{ Lebanon } & \multicolumn{2}{|c|}{ Morocco } \\
\hline & 1990 & 2000 & 1990 & 2000 & 1990 & 2000 & 1990 & 2000 & 1990 & 2000 & 1990 & 2000 \\
\hline $\begin{array}{l}\text { Total revenues } \\
\text { Of which: }\end{array}$ & 28.8 & 38.5 & 24.4 & 22.8 & 17.5 & 33.0 & 26.5 & 25.9 & 14.1 & 24.5 & 23.0 & 24.0 \\
\hline $\begin{array}{l}\text { Tax revenues } \\
\text { Of which: }\end{array}$ & 12.6 & 8.5 & 16.7 & 16.0 & 4.7 & 5.8 & 14.1 & 16.1 & 9.2 & 16.6 & 20.8 & 22.2 \\
\hline $\begin{array}{l}\text { Tax on income } \\
\text { and profits }\end{array}$ & 3.9 & 2.0 & 4.4 & 6.0 & 2.4 & 3.2 & 4.2 & 2.7 & 1.3 & 2.9 & 5.5 & 7.2 \\
\hline $\begin{array}{l}\text { Tax on goods } \\
\text { and services }\end{array}$ & 6.0 & 4.0 & 3.1 & 6.0 & 0.7 & 1.0 & 3.3 & 7.8 & 0.8 & 9.3 & 10.6 & 9.7 \\
\hline \multirow[t]{3}{*}{ Other } & 2.8 & 2.5 & 9.2 & 4.0 & 1.6 & 1.6 & 6.6 & 5.6 & 7.1 & 4.4 & 4.7 & 5.3 \\
\hline & \multicolumn{2}{|c|}{ Mauritania } & \multicolumn{2}{|c|}{ Pakistan } & \multicolumn{2}{|c|}{ Saudi Arabia } & \multicolumn{2}{|c|}{ Sudan } & \multicolumn{2}{|c|}{ Tunisia } & \multicolumn{2}{|c|}{ Yemen } \\
\hline & 1990 & 2000 & 1990 & 2000 & 1990 & 2000 & 1990 & 2000 & 1990 & 2000 & 1990 & 2000 \\
\hline $\begin{array}{l}\text { Total revenues } \\
\text { Of which: }\end{array}$ & 22.5 & 26.2 & 18.8 & 12.3 & 36.8 & 30.2 & 7.7 & 11.7 & 26.8 & 29.1 & 18.2 & 37.9 \\
\hline $\begin{array}{l}\text { Tax revenues } \\
\text { Of which: }\end{array}$ & 18.1 & 15.0 & 14.0 & 12.9 & 2.6 & 2.1 & 5.7 & 5.8 & 19.5 & 26.0 & 8.0 & 7.2 \\
\hline $\begin{array}{l}\text { Tax on income } \\
\text { and profits }\end{array}$ & 6.4 & 4.9 & 1.7 & 3.4 & 0.5 & 0.3 & 1.4 & 1.3 & 3.3 & 5.6 & 1.9 & 2.6 \\
\hline $\begin{array}{l}\text { Tax on goods } \\
\text { and services }\end{array}$ & 3.6 & 7.4 & 5.9 & 6.8 & 2.1 & 0.8 & 1.8 & 2.0 & 6.6 & 11.1 & 2.9 & 2.7 \\
\hline Other & 8.1 & 2.7 & 6.4 & 2.5 & -- & 1.0 & 2.5 & 2.5 & 9.6 & 9.3 & 3.2 & 1.9 \\
\hline
\end{tabular}

Source: IMF staff compilations.

\footnotetext{
${ }^{7} 1990$ is actually 1989-90 for most countries, and 2000 is 1999-2000. For Saudi Arabia, it is 1992 and 2002. Lebanon is a special case: tax files were lost during the war, and efforts in the 1990s focused on customs reforms.
} 
Table 3. Trade Taxes as a Share of Total Tax Revenue, 1980-98

(Unweighted averages, in percent of total)

\begin{tabular}{lccc}
\hline & 1980 & 1990 & 1998 \\
\hline OECD & 4.7 & 2.7 & 1.1 \\
Non-OECD & 24.2 & 20.5 & 17.7 \\
$\quad$ Africa & 38.6 & 31.9 & 37.5 \\
Asia and Pacific & 29.0 & 27.6 & 19.2 \\
Middle East & 31.7 & 28.9 & 25.2 \\
Western Hemisphere & 24.9 & 14.3 & 14.2 \\
\hline
\end{tabular}

Source: Michael J. Keen, ed., Changing Customs (Washington: IMF, 2003).

\section{Petroleum issues}

Many countries in the Middle East have revenues available from mineral resources (especially hydrocarbon). For some countries, this has meant a reduced interest in (non-oil) tax revenues, and consequently little incentive to develop effective revenue administration. Historically, in some countries, little priority was given to the revenue administration and collection procedures for taxes and levies, which were often based on antiquated, ineffective systems (usually involving extensive negotiations between taxpayers and tax officials).

More recently, given the realization that oil and gas revenues are in fact exhaustible, volatile, and uncertain, the complex issues of sustainability and intergenerational resource allocation have led several countries to rethink the importance of tax revenues. Some Middle Eastern countries have now embarked on fiscal reforms intended to reduce their dependence on hydrocarbon revenue, and others will follow. As is the case for revenue reform instituted for any reason, this will entail establishing the proper tax policies and administrative structures for a modern and effective tax system based on voluntary compliance.

\section{Historical influences}

In many countries of the region, revenue administrations have also been influenced by the French and British revenue administration traditions. This has led to fragmented tax administrations, including: (1) the split of tax administration functions (e.g., in Morocco and Mauritania), with the collection function being assigned to the treasury (Comptabilité Publique), rather than the tax administration; and (2) the split of direct and indirect tax operations (e.g., in Egypt and Jordan until recently), with the responsibility for domestic tax operations (VAT and income tax) fragmented between two separate administrations. In the context of best international practice today, these fragmentation characteristics are considered ineffective and inefficient. Many countries in the region have realized that reforming these outdated organizational structures can lead to significant benefits, including more effective and efficient tax administration and improved taxpayer compliance. 


\section{The case of the VAT}

One of the most significant tax reforms in the Middle East over the past decade or so has been the introduction of the VAT. This is part of a worldwide phenomenon. In 1969, only 8 countries had a VAT; by 2004, this number had grown to 126. Prior to 1990, among the 13 Middle Eastern countries reviewed, only two had a VAT (Morocco and Tunisia). Today, seven more have been added (Algeria, Egypt, Jordan, Lebanon, Mauritania, Pakistan, and Sudan), and legislation has been drafted in three others (the Islamic Republic of Iran, Saudi Arabia, and Yemen). The revenue-raising potential of the VAT has been an obvious reason for its spread throughout the region. Indeed, worldwide experience shows that a welldesigned VAT, with a broad base, limited exemptions, a single rate, and a high threshold, can be an efficient revenue-raising instrument ${ }^{8}$ and a powerful vehicle to modernize the tax administration.

An IMF November 2000 study $^{9}$ has shown that VAT performance has been a major component in the growth of tax revenue in a number of developed and developing countries and that it constitutes a significant share of total revenues - on average, about 25 percent of total tax revenue and more than 5 percent of GDP. Box 1 below summarizes the key design features that are conducive to good VAT performance.

\section{Box 1. Key Design Features that Are Conducive to Value-Added Tax Revenue Performance}

Base. Standard advice is for a broad-based VAT with exemptions limited to basic health, education, and financial services. The consequences of exemptions, including those on retailers and service providers, are adverse. Experience shows that implementation of a consumption tax at the import and manufacturing stages creates definitional problems (what exactly is "manufacturing," and how should one treat a manufacturer with retail outlets?). Restricting the consumption tax to certain categories of goods and services limits the tax base (a large part of the economy escapes the tax net) and distorts commercial decisions.

Rate. Adoption of more than one positive rate and use of a zero rate for domestic transactions have a significant negative impact on tax administration. It also significantly increases taxpayers' compliance costs. Experience shows that the redistribution that can be achieved through indirect taxes is intrinsically limited. The key point here is that even if the poor spend a large proportion of their income on particular items such as food, the rich will typically spend a larger absolute amount, so a reduction in the rate actually transfers more money to the rich than it does to the poor. This is why the majority of "modern" VATs implemented in recent years have a single positive rate and a zero rate limited to exports.

Registration threshold. The level of the threshold at which registration for the VAT becomes compulsory is critical for its successful implementation. This is the case especially in countries with weak administrative capacity where it is obvious that the capacity of small businesses to issue invoices and maintain proper books and records is problematic. In these countries, absent a sufficiently high (turnover) registration threshold, implementation of an account-based, self-assessed VAT is unrealistic.

\footnotetext{
${ }^{8}$ And more so than any sales tax that may have been in place prior to the introduction of a VAT.

${ }^{9}$ Liam Ebrill, Michael Keen, Jean-Paul Bodin, and Victoria Summers, eds., The Modern VAT ( Washington: IMF, 2001).
} 
Table 4 reflects some of the wide diversity of experience in VAT (from November 2000), reflecting that, for example, the standard rate varied from 3 percent in Singapore to 25 percent in Denmark and Sweden. There is considerable variation in the yield of the VAT - several countries garner less than 1 percent of GDP in VAT revenue, while at least five raise over 10 percent of GDP.

Table 4. Value-Added Tax Features by Region, November 2000

\begin{tabular}{|c|c|c|c|c|c|c|}
\hline & $\begin{array}{c}\text { Middle East } \\
\text { and North } \\
\text { Africa }\end{array}$ & $\begin{array}{l}\text { Asia and } \\
\text { Pacific }\end{array}$ & $\begin{array}{c}\text { Sub-Saharan } \\
\text { Africa }\end{array}$ & $\begin{array}{c}\text { Latin } \\
\text { America }\end{array}$ & EU & $\begin{array}{c}\text { Central } \\
\text { Europe and } \\
\text { CIS } \\
\end{array}$ \\
\hline Standard rate & 15.7 & 10.4 & 16.1 & 13.5 & 18.8 & 20.2 \\
\hline VAT revenues: & & & & & & \\
\hline $\begin{array}{l}\text { (a) in percent of } \\
\text { GDP }\end{array}$ & 5.7 & 3.3 & 3.9 & 4.9 & 7.0 & 6.4 \\
\hline $\begin{array}{l}\text { (b) in percent of } \\
\text { total revenue }\end{array}$ & 28.1 & 21.7 & 28.4 & 33.0 & 20.7 & 27.8 \\
\hline
\end{tabular}

Source: IMF staff calculations.

As evidenced in Table 5, in the Middle East today there is also wide diversity in the characteristics and results of the VAT:

The standard rate varies from a high of 20 percent in Morocco to a low of 10 percent in Egypt, Lebanon, and Sudan.

$\checkmark$ Four countries have a single positive rate, and five have multiple positive rates.

$\checkmark$ Registration thresholds range from EUR 21,000 in Sudan to EUR 90,000 in Lebanon.

$\checkmark$ Revenue as a percent of GDP ranges from 1.2 percent (Sudan) to 7.1 percent (Tunisia).

Table 5. Characteristics of the Value-Added Tax in Middle Eastern Countries, 2004

\begin{tabular}{lccccccc}
\hline & $\begin{array}{c}\text { Year of } \\
\text { Adoption }\end{array}$ & $\begin{array}{c}\text { Extended to } \\
\text { Retail and } \\
\text { Services }\end{array}$ & $\begin{array}{c}\text { Standard } \\
\text { Rate } 1 /\end{array}$ & Other Rates & $\begin{array}{c}\text { Threshold } \\
\text { (In euros) }\end{array}$ & $\begin{array}{c}\text { Collections } \\
\text { (In percent } \\
\text { GDP) }\end{array}$ & $\begin{array}{c}\text { Collections } \\
\text { (In percent } \\
\text { total) }\end{array}$ \\
\hline Algeria & 1992 & Partly & 17 & 7 & 43,000 & 3.1 & 21.0 \\
Egypt & 1992 & Partly & 10 & $5,15,25,30,45$ & 25,000 & 5.6 & 18.0 \\
Jordan & 1994 & Yes (in 2001) & 16 & 4,7 & 90,000 & 4.5 & 24.0 \\
Lebanon & 2002 & Yes & 10 & & 90,000 & 6.0 & 34.0 \\
Mauritania & 1995 & Yes & 14 & & 45,000 & 3.5 & 23.3 \\
Morocco & 1986 & Yes & 20 & $7,10,14$ & 18,000 & 6.0 & 28.5 \\
Pakistan & 1990 & Yes (in 1998) & 15 & & 80,000 & 4.6 & 18.0 \\
Sudan & 2000 & Yes & 10 & & 21,000 & 1.2 & 20.0 \\
Tunisia & 1988 & Yes & 18 & $6,10,29$ & 70,000 & 7.1 & 25.3 \\
\hline
\end{tabular}

Source: IMF staff calculations.

1/ The standard VAT rate (unsurprisingly) has a significant impact on revenue.

${ }^{10}$ A higher threshold (EUR 200,000) is applied to retailers. 
Despite this diversity, and while both inter- and intraregional comparisons can be affected by many factors, two conclusions emerge: the VAT has an important impact on tax revenues in Middle Eastern countries, and VAT performance in these countries compares well with developing countries and transition economies.

Other important issues associated with the VAT (including design, organizational structures, and impacts of the VAT on the reform of tax administration) are discussed below.

\section{Revenue Administration Reform And Policy Issues}

\section{Role of revenue administration, and the need for reform}

The role of revenue administration (tax and customs) is to collect taxes as specified in the law. ${ }^{11}$ However, how the administration goes about this responsibility is critically important to the effectiveness of the tax laws themselves. Until the early 1990s, it was thought by many that strong enforcement was the key to successful revenue administration. In today's context, it is considered that an effective and efficient revenue administration is one that will ensure compliance through a balance of reliable services and education, and targeted audit and enforcement activities.

When this objective is achieved, a modernized revenue administration will be characterized by a function-based structure with a strong headquarters, fully automated business processes, risk-based compliance programs, and skilled and professional staff acting with fairness, honesty and transparency. The revenue administration will maximize the collection of taxes according to the law, at the lowest acceptable cost to the government (administrative cost) and to the taxpayer (compliance cost), and will be adequately resourced, effectively managed, and independent from political processes.

This overall objective is valid for all countries, including those in the Middle East. However, for many economies in the region and elsewhere significant effort is needed to achieve it. For this reason, most countries have embarked on programs of revenue administration reform, beginning in the 1980s for many developed countries, and in the 1990s for others. Most Middle Eastern countries began serious efforts at reform in the 1990s.

Based on experience, many benefits can result from revenue administration reform:

$\checkmark$ Improved revenue performance;

$\checkmark$ More equitable distribution of the tax burden across the community;

$\checkmark$ More consistency and fairness for business and individuals;

$\checkmark$ Greater ability to implement fiscal reforms;

$\checkmark$ Reduced compliance costs for taxpayers;

\footnotetext{
${ }^{11}$ In addition, customs has a major role to play in the protection of society. In recent years, the security role of customs administrations at the border has been increasingly emphasized. Furthermore, tax laws are sometimes used to deliver subsidies through refundable tax credits, although this is more common in OECD countries.
} 
$\checkmark$ An increase in the number of registered taxpayers;

$\checkmark$ A reduction in tax evasion and tax fraud;

$\checkmark$ Improved management of tax arrears;

$\checkmark$ Improved services to tax payers; and

$\checkmark$ Greater transparency and integrity in the administration's operations.

For revenue administration reform to be successful, critical requirements have to be met, including: a strong political commitment to reform, with clear decisions and the provision of necessary resources; professional and stable leadership; a willingness to abandon old, ineffective practices; and the establishment of a formal reform project with a clear achievable mandate, agreed objectives, and realistic timeframes. The absence of these requirements has impeded the progress of reform in several countries, including some in the Middle East.

Reforming revenue administration is neither quick nor simple. There are a great many challenges to be faced, and these tend to mirror the preconditions for success. Some of the major ones confronting most Middle Eastern countries include the following.

Low levels of compliance with the tax laws. A common challenge all countries face is the need to reduce noncompliance with tax laws. However, while noncompliance exists everywhere in a variety of forms, the lack of systems to identify critical compliance risks and the lack of capacity to develop and implement effective compliance strategies are significant matters of concern in most transition economies and developing countries.

A number of factors have an impact on compliance levels. For instance, public attitudes and respect for government institutions affect compliance, especially in countries where the payment of taxes has not been historically important or disciplined. The nature of the tax system - simplicity and stability of the laws and the tax rates - is also a major determinant in compliance. Other factors, ranging from the public perception that the government provides inadequate quality services to the degree of development of the banking systems and the effectiveness and efficiency of the revenue administration, are also important.

Insufficient political commitment. The lack of commitment to, and understanding of, reform efforts on the part of political leaders is another challenge faced by revenue administrators. Many features of revenue administration reform - such as streamlining the tax office networks, transferring collection responsibilities to the tax department, merging direct and indirect tax administrations within a single agency, and moving to postrelease audits to properly manage risk - have been opposed in several countries. Political leaders have also failed to take action to sustain reform, and sometimes have denied support to revenue administrations in using enforcement powers provided by the law.

A lack of capacity, expertise, and resources. There are examples of countries that have embarked on major reforms in the 1990s, often with considerable TA from donors, but their success has been impeded by restricted capacity in management and an insufficient level of expertise. The result has been an inability to sustain the initiatives that have been launched. Reform initiatives also require time, effort, and human and financial resources. Too often, the 
true costs of reform initiatives are not considered at the outset, with the result that initiatives lose momentum and incur extensive delays.

The role of customs. Customs administration in this paper deals with the revenue-related aspects of the work of customs in the Middle Eastern countries. While the customs role in relation to direct taxes is limited (consisting mainly of information exchanges with tax administrations and, in a few countries, collection of withholding income tax on imports), it has a crucial role with respect to indirect taxes. Since these taxes are generally levied on a destination basis, it falls on customs to play a key role in ensuring that commodities entering and leaving a country are subject to the appropriate tax regime. In this aspect, the role of customs has increased because of the spread of the VAT in several Middle Eastern countries.

Reform of customs administration has been every bit as much a worldwide phenomenon as tax administration reform, and the Middle East has been no exception. One key purpose of customs reform and modernization is to remove impediments to trade; in other words, to minimize administrative costs incurred by the government and compliance costs incurred by traders in a manner consistent with legislative and policy objectives. In the past, the whole process of assessing and collecting trade taxes was built around extensive physical inspection of shipments at points of entry. This process was often complicated by outmoded legislation and trade tax policies that involved extensive rate differentiation and pervasive exemptions. Prior to reform initiatives, customs administration was characterized by poorly designed procedures, an inability to exchange information with other branches of the revenue administration, widespread corruption, and poor relationships with the private sector.

Customs modernization and reform involve fundamental changes in the overall customs environment and in the way in which customs administrations discharge their mandates. Based on best international practice, ${ }^{12}$ changes are normally required in four key areas.

$\checkmark$ Establishing coherent trade policies and clear legislation. There is a requirement for well-designed policy measures and simple and transparent legislation that clearly describes the obligations and entitlements of traders and the powers, authorities, and responsibilities of the customs administration.

$\checkmark$ Adopting modern, simple procedures. Well-designed procedures are critical. They are also needed to ensure the effective application of policies, particularly where there can be threats to revenue or other policy objectives. For example, a partial list would include such aspects as goods in transit, exemptions, and temporary imports.

$\checkmark \quad$ Increasing self-assessment by traders, supported by a movement away from physical and toward postrelease controls. With voluntary compliance the critical component of modern revenue administration, self-assessment by the trader must be established.

\footnotetext{
${ }^{12}$ Michael Keen, ed., Changing Customs: Challenges and Strategies for the Reform of Customs Administration, (Washington: IMF, 2003).
} 
Traders declare and pay the taxes due and the customs administration adopts a system of risk-based, ex-post checks on the declarations. This means a de-emphasis on physical inspections at the point of entry with effective control after the goods have been cleared.

\section{$\checkmark \quad$ Ensuring organizational structures and human resources practices conducive to} effectiveness and integrity in customs administration. The customs administration must be free of political interference, have a clear mandate in the law, and be organizationally placed so that it can interact in concert with other branches of revenue administration. Customs should have a leading role at the border on behalf of other agencies. The human resources regime, including issues such as remuneration, code of conduct, and discipline, must be clearly articulated and rigorously applied.

Customs administrations around the world, including many in the Middle East have concluded that reform of this nature requires both political commitment and comprehensive strategic planning.

\section{Policy issues}

Tax policy is a critical responsibility for all ministries of finance. For some time now it has been recognized that effective tax policy can never be a reality without an effective tax administration, and that administrative capacity to implement tax laws is a prime determinant of the results those laws will produce. ${ }^{13}$

Experience with tax reform initiatives undertaken by countries in the past decade shows that tax policy changes can only provide the expected results when sufficient attention has been paid to implementing appropriate administrative support. The experience of Commonwealth of Independent States (CIS) countries in which a VAT law was hastily introduced in the early 1990s illustrates this kind of problem. In some cases, tax authorities are still struggling to administer the VAT properly, and it has not yet been possible to establish the conditions for an account-based, self-assessed VAT. Similarly, many of the African and Middle Eastern countries that were advised by tax policy experts to introduce a global income tax in the early-1990s have not yet been able to establish the systems needed to ensure the effective control of a taxpayer's global income.

It is equally true that complexities in tax laws can compromise tax administration. In many cases, complex and complicated measures offer only marginal advantages from a tax policy perspective with disproportionately high inefficiencies in administration, and a resulting reduction in overall effectiveness. For Middle Eastern countries, some of the tax policy concerns influencing tax administration are set out below.

\footnotetext{
${ }^{13}$ As Bird and Casanegra de Jantscher put it in the early 1990s, "Policy change without administrative change is nothing..." (Richard M. Bird and Milka Casanegra de Jantscher, Improving Tax Administration in Developing Countries; Washington: IMF, 1993).
} 
Simplification of VAT laws. Notwithstanding the encouraging results achieved with the VAT in some Middle Eastern countries, there is still a significant need to improve the structure of this tax. Common problems include registration thresholds that are too low (and, in some countries, multiple thresholds), an unnecessarily complex rate structure, and too many exemptions. However, there are some encouraging trends in these areas including a move toward broadening VAT bases, including retail and services (e.g., in Jordan, Lebanon, Pakistan, Morocco, and Mauritania); some countries have substantially increased registration thresholds (e.g., in Jordan, Lebanon, and Pakistan); and there has been some movement toward a single rate structure (e.g., in Lebanon, Mauritania, Pakistan, and Sudan).

Elimination of exemptions. The widespread use of tax exemptions in Middle Eastern countries, as in other transition countries, has an obvious negative impact on revenues. In addition to losses of revenue, tax exemptions contribute to the complexity and lack of transparency of tax systems and can lead to harmful tax competition, which may have a global, long-term negative impact on tax bases. The IMF has consistently advised in favor of broadening tax bases, decreasing tax rates, and providing appropriate depreciation and capital allowances to promote an environment conducive to investment, instead of granting concessions. In any case, when these concessions cannot be avoided, exemptions should be strictly limited in terms of coverage and duration to avoid widespread abuse.

Simplification of income tax. In some Middle Eastern countries, the move toward global income tax systems to replace schedular income taxes is still seen as desirable in the medium to long term. However, it is widely recognized that this reform should be adopted only when appropriate capacities to administer a modern income tax system have been developed (e.g., to support implementation of the new income tax law adopted in 2005, Egypt has embarked on a major reform to improve the capacity of the tax administration). In addition, the simplification of income tax systems has been a common trend together with a search for more effective taxation mechanisms, including withholding and presumptive taxation systems, the latter developed for small and hard-to-tax groups of taxpayers. For example, a simplified regime, the "forfait" has traditionally been applied to small taxpayers below a turnover threshold in most Francophone countries, including Algeria, Mauritania, Morocco, and Tunisia. Moreover, in implementing their income tax reforms, countries like Egypt and Lebanon are also developing simplified taxation system for their small taxpayers.

Trade policy. As noted earlier in this paper, there have been many changes in trade policy in the Middle East (e.g., Egypt, Lebanon, and Morocco) and elsewhere over the past 10 to 15 years. A good example is the desire and need to simplify customs tariffs and reduce the large number of rates that exist in many countries. This can have a significant impact in terms of effective administration and reducing the burden of compliance on taxpayers. Not only do customs administrations have to adapt to such changes, but the way in which they modernize their activities will have a direct impact on the effectiveness of trade policy reforms. For example, a fully modernized and effective customs administration will be the prime source of information for all trade-related statistics. Most customs administrations have this responsibility, and their support is crucial for an effective trade policy function. In addition, customs administrations are required to provide important input on the 
enforceability of trade policy changes being considered. Finally, the effectiveness with which customs administrations carry out their basic functions such as classification, valuation, and origin determination has a major impact on the effectiveness of basic trade and tax policies.

Historically, some customs administrations have been hesitant to embrace modernization. There appear to be two main reasons for such resistance to change. The first, a common problem, is a general resistance to the inevitable organizational disruption that occurs in a modernization initiative. The second relates to the impact that simplified procedures and transparent operations could have on opportunities for corruption and other rent-seeking.

Customs administrations willing to modernize can reap significant benefits in terms of more effective and efficient tax and trade policy administration. Successful reform will require a significant redeployment of resources and energies toward new or revised functions: a strengthening of valuation capabilities; a reduction in physical inspections with the introduction of risk profiling and targeting systems to support post-clearance audits; improved origin determination; and major improvements in monitoring exemptions and suspensive regimes.

\section{Reform Effort OVer the Past Ten Years in the Middle East}

\section{Tax administration}

As a means of assessing tax administration performance over the past decade or so, Appendix I identifies certain features of tax administration in the countries reviewed, and summarizes the status of these features in the early 1990s versus today. These features represent areas where FAD has provided tax administration recommendations to Middle Eastern countries over the past decade. By looking at the situation in the early 1990s and comparing it with today, a snapshot emerges of the overall extent of tax administration reform and modernization. This appendix presents a high-level summary, which, by definition, cannot describe all the nuances of each category. It is a "best-fit" exercise only. ${ }^{14}$ Based on this information, it is possible to form some initial conclusions about progress in the Middle East in each of the tax administration areas.

Reform strategy. Not a single country of those surveyed can be said to have had in place a detailed and comprehensive tax administration reform strategy more than a decade ago. Now, nine have a full reform plan in place, and two others have a strategy considered to be in its early stages. Traditionally, developing and transition economies have a critical weakness in their lack of capacity for strategic planning, and reform efforts will be suboptimal without addressing this concern. This is a major reason why FAD has more recently focused on upstream $^{15}$ or strategic TA, in coordination with other donors that support implementation of

\footnotetext{
${ }^{14}$ Appendix III presents cases studies providing details for six of the countries reviewed.

15 "Upstream" refers to the notion of providing TA at the strategic or direction-providing stages.
} 
the revenue administration reform programs. Delivering these programs still represents a major hurdle for countries in the Middle East, but the strategic processes and the political commitment have come a long way in several of them.

$\boldsymbol{V A T}$. The statistics on the VAT were discussed earlier in this study and have been included in Table 6 in Appendix I to provide as complete a picture as possible. In countries with an integrated, function-based tax organization, it is important to note the impact that introduction of the VAT has had on other aspects of tax administration, from introduction of self-assessment and reorganization of the tax administration to taxpayers services and enforcement programs, and development of information technology (IT) strategies. Many of these are referenced in the sections below.

Self-assessment. Self-assessment refers to a system of voluntary compliance whereby taxpayers comply with their basic tax obligations without intervention from a tax official, based on information they receive about their tax obligations. The taxpayer completes a tax return to accurately identify all tax liabilities and submits it voluntarily with the payment. When this does not occur, the tax administration takes the appropriate enforcement action. The principle of voluntary compliance is grounded in two key ideas: tax administrations have limited resources, and taxpayers have the best information about their tax liabilities. There are many advantages of self-assessment: reduction in the cost of tax administration; opportunity to use staff more effectively; fewer taxpayer disputes; speedier collection of revenue, combined with proper risk-based audit, more effective deterrence and detection of evasion; and potential increases in overall revenue. Tax system design should therefore reflect this reality.

In the Middle East a decade ago, only four countries could be said to have a basic self-assessment system-Algeria, Mauritania, Morocco, and Tunisia. Now, Jordan and Pakistan can be added to the list of those with a self-assessment system, with a further four countries having introduced self-assessment in connection with the VAT (Egypt, ${ }^{16}$ Lebanon, Sudan, and Tunisia), and some self-assessment efforts having been started or planned in the Islamic Republic of Iran, Saudi Arabia, and Yemen. Despite a history of resistance to self-assessment ${ }^{17}$ in developing countries, the Middle Eastern countries have made realistic progress in introducing self-assessment, although this progress is almost entirely an offshoot of the VAT.

Function-based organization. In many countries, the administration of domestic (both direct and indirect) taxes has been structured along a functional basis. This involves consolidating

\footnotetext{
${ }^{16}$ Self-assessment for income tax in Egypt is also currently developed.

${ }^{17}$ Resistance to self-assessment on the part of tax officials and policymakers is often a result of perceptions about the illiteracy of small traders in low-income countries, inadequate education of businesses in tax matters, and lack of confidence that taxpayers would be willing to pay voluntarily. Nevertheless, experience has shown that self-assessment systems, administered properly, are actually much more effective in addressing these issues than other systems, and do so in a way that minimizes opportunities for collusion, so rampant in other systems.
} 
activities and resources based on business processes and commonality of function, such as audit, collection enforcement, and taxpayer services. Strong functional units are established in headquarters with a capacity for strategic and operational planning, technical advice, performance measurement, and monitoring and evaluation. This produces improved management and control, effective specialization, economies of scale, better use of infrastructure and facilities, and simpler and more consistent treatment of taxpayers.

In the Middle Eastern countries a decade ago, only some of the French legacy countries (e.g., Algeria and Morocco) had function-based organizations. By 2004, both Jordan and Pakistan moved forward to introduce functional organizations for tax administration; Egypt, Sudan, and Lebanon had done so in respect of VAT. Afghanistan is planning a functional approach. A total of 11 of the 13 countries reviewed either have moved or are now moving toward function-based organizations.

Integrated direct and indirect tax administration. A key strategic recommendation of FAD over the past ten years has been the integration of direct and indirect tax administration, or more specifically the integration of VAT and income tax administration. There are demonstrable advantages to this type of organization, which: (1) facilitates implementation of function-based operations; (2) reduces the costs and compliance burden for taxpayers, and permits more efficient operations for the tax administration; (3) increases the effectiveness of tax administration with common registration, collection, and audit functions; and,

(4) facilitates synergies when modern practices for VAT can be levered to the entire tax organization. Of 126 countries that currently have a VAT:

$\checkmark 115$ have a tax administration that integrates the collection of VAT with income taxes.

$\checkmark 9$ have a stand-alone VAT department.

$\checkmark 2$ have VAT administered in a customs and excise department. ${ }^{18}$

The issue of integration is particularly relevant where a country has introduced a VAT. As noted earlier, in the Middle East, nine countries have a VAT (Algeria, Egypt, Jordan, Lebanon, Mauritania, Morocco, Pakistan, Sudan, and Tunisia), and legislation has been drafted in three others (the Islamic Republic of Iran, Saudi Arabia, and Yemen). Of the 13 countries reviewed, 5 already have an integrated tax administration (Algeria, Jordan, Morocco, Tunisia, and Mauritania), and 5 others have developed elements of integration or are planning to integrate their organizations (Egypt, the Islamic Republic of Iran, Lebanon, Pakistan, and Yemen).

\footnotetext{
${ }^{18}$ This is a legacy of the British approach to domestic tax administration where separate organizations were established for income taxes (Inland Revenue) and for customs operations and excises (Customs and Excise). Subsequently, when the VAT was introduced, responsibility for its administration was added to Customs and Excise. However, the United Kingdom has recently decided to merge VAT and income tax administration.
} 
Large taxpayer offices (LTOs). A special office for large taxpayers, within the tax department, has long been advocated for the domestic tax administration. Such an office reduces noncompliance among large taxpayers and ensures better services to them, serves as a pilot to introduce administrative changes (e.g., a function-based organization and selfassessment), reflects critical differences between large taxpayers and others, and provides an appropriate focus on the majority of a country's tax revenues. FAD recommends full-service LTOs as the means of achieving these desired objectives. In the early 1990s, none of the countries surveyed had a separate office for large taxpayers. Today, 10 countries (Egypt, the Islamic Republic of Iran, Jordan, Lebanon, Mauritania, Morocco, Pakistan, Saudi Arabia, Sudan, and Yemen) have a LTO and 2 (Afghanistan and Algeria) are planning to establish one.

Other segmentation - medium-size and small taxpayers. It is now widely recognized that a function-based organization is more effective than a tax-type organization. Additionally, a recent trend in several countries is to also orient the tax administration organization around key segments of the taxpayers. These countries have established special offices and/or programs to deal with specific segments of taxpayers, such as large taxpayers, medium-size businesses, and small enterprises and individuals. ${ }^{19}$ In these countries, the tax administration organization uses a combination of segment-type and function-type criteria, which allows the tax administration to improve the allocation of the available resources and its programs by tailoring them to the compliance pattern of different segments of taxpayers (Box 2).

In the Middle Eastern countries, there have been some developments in further taxpayer segmentation beyond that for the largest taxpayers. Algeria and Jordan are considering the creation of special offices for medium-size and small taxpayers, and plans are being formulated for a taxpayer segment approach in Afghanistan, Egypt, Morocco, and Pakistan. These efforts represent the very first inroads into additional taxpayer segmentation in the Middle East, which lags behind other regions in this aspect of tax administration reform.

TIN. A unique taxpayer identification number (TIN) controlled by the tax administration and used for all taxes, including those collected at importation, is essential for an effective tax administration. None of the surveyed countries had a proper TIN in the early 1990s, and today eight countries (Afghanistan, Egypt, Jordan, Lebanon, Mauritania, Morocco, Pakistan, and Saudi Arabia) have introduced a TIN that meets the above definition. Sudan and Yemen have made some progress but still have a certain distance to go. It is clear, however, that in the region the full utilization of a unique TIN is proving difficult for many tax administrations.

\footnotetext{
${ }^{19}$ Typically, large taxpayers account for 60-70 percent of total tax collections, medium-size taxpayers for 2530 percent; and small taxpayers for less than 5 percent.
} 


\section{Box 2. Taxpayer Segmentation}

While a functional and integrated approach to tax administration leads to better utilization and deployment of resources than fragmented and outdated structures, there is also a need to recognize the different risks, requirements, and contribution to overall revenue of the various segments of the taxpayer population. It is vitally important for a tax administration to understand its client base, particularly the different segments that constitute the taxpayer population. The advantages of this approach include: (1) strengthened accountability for organizational outcomes; (2) allocation of resources based on risk to revenue; and, (3) better matching of enforcement, service, and educational programs to specific types of taxpayers.

The large taxpayers are typically distinct legal entities. They are few in number but often with many employees; have high turnover; are often involved in complex international transactions, perhaps through subsidiaries or related companies; may wield influence within government circles; and maintain proper books and records, but with professional accounting and legal assistance to interpret the law to their advantage. The importance of large taxpayers to revenue is clear. If compliance for this group declines, the impact can be substantial. This is why, in recognition of the importance of large taxpayers, many countries have instituted special measures for this segment, usually by establishing a large taxpayer office (LTO).

In contrast, a moderate number of medium-size businesses often have less formal structures, such as sole proprietorships or partnerships; fewer employees; and moderate levels of business activity that are often cash based, but with possibly less diligent bookkeeping resulting in opportunities to underrecord income and evade tax. The demarcation between the large, medium, and small taxpayer segments can sometimes be obscure. However, in many countries the dividing lines are based on turnover and a cutoff is determined for the largest taxpayers. A cutoff point for the medium taxpayer segment is often deemed to be the VAT registration threshold in view of the record-keeping obligations for VAT.

A potentially much larger segment of small businesses poses many difficulties to identify, regulate, and ensure that they contribute something to revenue that is commensurate with their size and capacity to pay. In developing countries, a large share of this group is considered to be in the informal sector. They are almost universally cash based. Often proper record-keeping is nonexistent, and the whereabouts of taxpayers difficult to determine. In some countries, simplified tax provisions apply to small businesses that fall in this segment, in the form of presumptive taxation, often based on the approximate turnover of the business. Ideally this should approximate and substitute for all indirect and direct tax obligations in a single obligation that is easy to comply with and simple to administer.

Taxpayer services. FAD has always recommended that improving services to taxpayers is critical as a support to the self-assessment system, and hence to the effectiveness of tax policies. Services assessed as part of this review include taxpayer registration and the maintenance of related data files, as well as taxpayer education (development of better information programs especially for small taxpayers and new businesses, simplification of forms and procedures including the elimination of requests for unnecessary data, training of tax officials on changes required to develop a more taxpayer-friendly approach, and the establishment of formal taxpayer rulings systems). Historically, the taxpayer service functions have been very weak in developing and transition countries, and their importance has been underestimated.

In the Middle Eastern countries under review, these services are assessed as being poor or basic in the early 1990s. In 2004, some progress is evident, especially because service 
improvements is one of the most difficult areas in which to change historically entrenched attitudes and organizational cultures. One country (Jordan) has been assessed as improved, and six others (Algeria, the Islamic Republic of Iran, Mauritania, Morocco, Sudan, and Yemen) have implemented minor improvements. In addition, both Egypt and Lebanon have been assessed as improved because of service enhancements introduced in their respective VAT administrations.

Tax operations. The review has focused on the following issues: (1) control and management of arrears, including development of debt control strategies, prompt detection of delinquent taxpayers, classification of arrears by size and by age, and strict monitoring of enforcement actions; (2) VAT refunds, encompassing accelerated refund procedures for exporters and investors, and implementation of risk analysis methods to focus pre-refund audit on highest risk; and (3) audit, including development of better selection methods, development of audit programs based on risk, and strengthening the audit function at headquarters.

Tax operations in almost all Middle Eastern countries have been assessed as basic in the 1990s. In most cases, all the tax operation functions were present but were implemented in outmoded and inefficient ways, with little or no support for self-assessment. By 2004, there is again evidence of good progress. Four countries are assessed as improved (Algeria, Jordan, Egypt, and Lebanon, the last two primarily because of improvements related to VAT), and five as having brought in minor improvements.

Information technology. Many tax administration reforms developed in the past ten years have given a strong focus to computerization. Many have believed that automation alone would be the key to modernizing operations. However, this is not the case. The automation of obsolete and inefficient processes has been particularly disastrous in tax administration. There is widespread acceptance now of the notion that a comprehensive review and redesign if necessary of business processes (usually to eliminate, reduce, and simplify) must take place before automation is undertaken. In fact, such activities are a pre-requisite to the development of IT strategies.

Ten years ago, the IT strategy for all countries in the Middle East could be described as poor, or nonexistent, for all the countries reviewed. There have been a number of improvements since then: Egypt and Lebanon have made significant improvements with the system acquired for the VAT, although it is not yet being used for income tax; Jordan is planning improvements; and some improvements have taken place in Morocco, Pakistan, Saudi Arabia, and Sudan.

\section{Customs administration}

Similar to the methodology used for tax administration, Appendix II identifies certain features of customs administration in 10 of the 13 countries reviewed, and summarizes the status of these features in the early 1990s versus today. These features generally represent areas where FAD has made customs administration recommendations in its TA over the past decade. By looking at the situation in the early 1990s and comparing it with today, a picture 
can be formed of the overall extent of customs administration reform and modernization. As was the case for tax administration, Appendix II presents a high-level summary that, by definition, cannot describe all the nuances of each category. It is a "best-fit" exercise only. On the basis of this information, it is possible to form some initial conclusions about progress in the Middle East in each of the customs administration areas.

Reform strategy. None of the ten countries reviewed had in place a comprehensive customs administration reform strategy more than a decade ago. Now, nine have a full reform plan in place, and the tenth has a strategy considered to be in its early stages. Similar to the situation in tax administration, developing and transition customs administrations have a critical lack of capacity for strategic planning on which the success of reform efforts will often hinge. Establishing a formal reform strategy is always the first step.

Customs law. The legislation governing customs operations and often the organization of the customs function in the government is the customs law or code. As noted in the previous section, clear and simple legislation is critical to an effective customs administration. In the 1990 s, eight of the ten countries were considered to have legislation adequate for the customs activities of the day. Today, given the rapidly changing environment, six have revised their customs legislation, and the remainder have reviews under way or planned.

Customs procedures. Customs procedures characterized by repetitive checking, unnecessary complexities, and a lack of transparency constituted one of the prime drivers for customs reform. Ten years ago, five of the ten countries reviewed were considered to have overly complicated and unclear customs procedures, two others met basic requirements only, and three were considered adequate at that time. Now, seven are considered as having shown improvement (Egypt, Jordan, Lebanon, Morocco, ${ }^{20}$ Pakistan, Sudan, and Yemen), with two others having minor improvements.

Post-release verification. This category remains one of the weakest areas for customs reform for the Middle East. At issue here is the existence of risk-based controls exercised after goods have been cleared for entry, with a deemphasis on non-risk-based physical inspection at points of entry. Ten years ago, none of the countries under review had any effective postrelease verification procedures. Today, Morocco has implemented these reforms, and Jordan and Lebanon are listed as much improved. However, while plans exist in some areas, the other countries have made relatively little progress in this area.

Effective organization. This overall category is designed to capture an assessment of the organizational structures and institutional processes that are conducive to integrity and effectiveness in customs administration. In the early 1990s, only one or two of the countries

\footnotetext{
${ }^{20}$ As indicated in Appendix II, modernization of the customs administration in Morocco is considered as a very successful reform, which included an improved customs code, streamlined and simplified procedures, implementation of control based on risk assessment, performance standards, and effective internal audit, effective use of information technology, and a consultation process with the private sector.
} 
had organizations and processes that were efficient, modern, and structured to ensure integrity. Today, about half the group is considered to have made improvements in these areas, while the other half still has a long way to go.

Information technology. IT investments are as important for customs administration as they are for tax administration. A number of customs application software systems are available, and where they have been effective they have been adapted to reengineered and simplified business processes. The situation ten years ago was that all but one of the countries reviewed had only basic IT systems for their customs operations. Today, all the countries recognize the importance of IT, with five having the most modern systems (ASYCUDA ++ or better), and four others having made a number of improvements.

\section{Assessment and Evaluation}

This section will provide observations on progress in tax and customs administration reform, discuss the impact of IMF recommendations on progress made, and draw conclusions about the revenue administration aspects of Middle Eastern countries in general

\section{Main observations}

With respect to tax and customs administration reform, specifically over the past ten years, the main comments are as follows.

- $\quad$ Despite the challenges in the Middle East, several governments have committed to strong programs of reform. While the interest in tax and customs administration reform may have been late in coming to the Middle East compared with other regions, there have clearly been developments over the past ten years that demonstrate a high level of interest. The spread of the VAT, the renewed interest in non-oil revenues, and a general push toward modernization of government institutions have all contributed.

- $\quad$ The development of reform plans for both tax and customs administration has been a feature in almost every country. Part of the process of committing to reform is the formalization of plans and strategies to implement new initiatives. This formalization is now a feature of all countries in the region, although the degree to which they have been successful varies considerably from country to country.

- $\quad$ The spread of VAT and its positive influence on the modernization of tax administration has been a major development. To the extent that tax administration reform has taken hold in Middle Eastern countries, it is evident that much of the progress is due to the introduction of the VAT. Administrations have used the occasion of the VAT to develop new businesses processes, including the taxpayer services and audit programs needed for the operations of an account-based, selfassessed tax. However, unless integrated organizations have been established to administer both direct and indirect domestic taxes, these positive developments have 
not benefited the income tax administration that remains in many countries outdated, inefficient, and extremely ineffective in terms of desired tax policy outcomes.

- $\quad$ Introduction of self-assessment has been steady due to the influence of the VAT, but in several Middle Eastern countries, income tax regimes are not yet based on selfassessment concepts. The self-assessment nature of the VAT has by definition led to the introduction of modern procedures and systems in countries where this tax was implemented. However, the income tax remains based largely on administrative assessment and antiquated, burdensome procedures in countries with a tradition of separate administration for direct and indirect taxes. Moreover, experience in these countries usually shows that tax regimes that do not use self-assessment are more susceptible to corruption.

- $\quad H o w e v e r$, integration of domestic tax administration is moving forward in more than half of the countries surveyed and function-based organizational structures for tax administration are gradually becoming prevalent in the Middle East. The evolution of tax administration structures to modernized organizations based on common functions has taken hold in the Middle Eastern countries. Crucial integration initiatives (unifying all domestic tax operations and functions within an integrated, function-based structure) are less well advanced, but integration will be a fact in the near future for at least 60-70 percent of the countries surveyed.

- $\quad$ Segmentation efforts have begun in several countries, initially with establishment of LTOs in most of the countries surveyed. In most of the countries surveyed, LTOs have been or are being implemented for the large taxpayers (i.e., those 800-1,000 taxpayers usually responsible for 60-70 percent of tax collections). Implementation is uneven across the region, but the concept has been embraced with only few exceptions.

Moreover, further segmentation, such as for medium or small taxpayers, is also beginning in some of the more progressive tax administrations. In these countries, a high threshold has been adopted to differentiate small and medium-size taxpayers:

$\checkmark \quad$ Small taxpayers with a turnover below the threshold are exempt from VAT, have simplified bookkeeping obligations, and are subject to a simplified taxation regime.

$\checkmark \quad$ Taxpayers with a turnover above the threshold (i.e., both medium-size and large taxpayers administered by the LTO) are subject to VAT and to the "normal" income tax regime, using modern procedures based on self-assessment principles.

- $\quad$ The implementation of an adequate TIN has not been particularly successful in several Middle Eastern countries. In many cases there appear to be difficulties with cooperation with other agencies responsible for corporate registration. 
- $\quad$ Only minor improvements have been made in critical taxpayer service areas while improvements in taxpayer operations, especially related to VAT, have generally been launched as part of reform programs. Taxpayer services, as a critical underpinning for self-assessment, generally remain weak with the few success stories usually revolving around VAT implementation. On the other hand, good progress has been made in addressing other operations such as accounting and payment, enforced collection, and in a few cases, audit.

- $\quad$ The full exploitation of IT for tax and customs administration has not occurred. While all countries are, to some extent, using automated systems in their tax and customs administrations, the concept of business decisions driving IT requirements remains elusive. This is especially true in tax administration where the specific headquarters functions need to emerge as the business process owners to provide requirements to IT specialists.

- $\quad$ Customs laws and procedures have generally been improved, but risk-based postrelease verification programs have not been fully implemented. Many Middle Eastern countries have responded to recommendations to shore up the legislative and procedural inconsistencies in their customs regimes, which is always the first place to start. They have taken advantage of strong examples from other countries to review legislation, and introduce improvements such as the single administrative document approach. However, the movement to risk-based post-release verification lags much further behind.

\section{IMF technical assistance}

In all of the countries reviewed, the IMF (FAD) has provided some level of TA over the period of the survey. One issue to consider is the impact of the IMF recommendations in the progress that has been made.

When evaluating the effectiveness of IMF TA in the revenue administration area, it is important to consider the change that was introduced in the mode of delivery of this assistance in recent years. Until 1998-99, long-term advisors were sometimes assigned by the IMF to support revenue administration reforms in a number of countries (e.g., among the countries surveyed, the Islamic Republic of Iran, Saudi Arabia, and Yemen). Since then, most of the IMF's revenue administration assistance is now provided through missions organized from headquarters, and regional and short-term experts, using an "upstream" approach. $^{21}$

\footnotetext{
${ }^{21}$ The assignment of a regional revenue administration advisor in the IMF's Middle East Technical Assistance Center (METAC) that was created in October 2004 has enhanced this approach in several countries covered by the center (e.g., Egypt, Jordan, Lebanon, Libya, Sudan, Syria, West Bank and Gaza, and Yemen). Through frequent contacts with tax authorities and TA providers in the region, the advisor has been particularly instrumental in (1) identifying reform needs; (2) coordinating the revenue administration assistance provided by the IMF (FAD and the METAC) with others donors; and (3) providing follow-up assistance to implement major reforms.
} 
The objective of this approach is to increase the IMF capacity to provide strategic advice during review-diagnostic missions and support implementation of revenue administration reforms through follow-up missions and visits of senior experts as needed. Experienceparticularly in countries covered by the present survey, including Afghanistan, Egypt, Jordan, Lebanon, Morocco, and Pakistan - shows that this approach has allowed a more effective coordination of the TA provided by the IMF, the World Bank, and other donors (e.g., the EU, France, the UK-DFID, and the USAID). Interestingly, this approach has also resulted in additional incentives for governments to take stronger ownership of the IMF-recommended reforms by establishing properly staffed project structure to manage the reform process and by taking appropriate action to secure continuation of the IMF support. ${ }^{22}$

This approach has proved to be the more cost-effective in countries where implementation of a tax reform strategy is critical for Fund programs. The progress noted for the Middle Eastern countries where the upstream approach was used-including Jordan, Lebanon, Morocco, Pakistan, Sudan, and more recently Egypt — are encouraging. While accountability for success or failure rests, of course, ultimately with the authorities, there are clear signs that the IMF's revenue administration advice has been instrumental in several countries, including:

$\checkmark$ Development of reform strategies in the majority of the countries surveyed;

$\checkmark$ VAT implementation (e.g., Lebanon, Jordan, Mauritania, Pakistan, and Sudan);

$\checkmark$ Implementation of integrated, function-based tax administration ${ }^{23}$ (e.g., Jordan, Mauritania, Morocco, and Pakistan);

$\checkmark$ Establishment of a LTO (Algeria, Afghanistan, Egypt, the Islamic Republic of Iran, Jordan, Lebanon, Morocco, Mauritania, Pakistan, and Yemen); and

$\checkmark$ Modernization of customs (Egypt, Jordan, Lebanon, Morocco, and Pakistan).

However, FAD has not been successful in convincing some countries to implement its advice in the following areas:

$\checkmark$ Adopting a modern VAT — with broad base and limited exemptions, a simple rate structure, and a high threshold — or improving an "old" VAT (e.g., Algeria, Egypt, Morocco, Tunisia, and Yemen); and

$\checkmark$ Implementing full self-assessment procedures - including more effective taxpayer services and audit programs based on risk management principles. While positive

\footnotetext{
${ }^{22}$ Continuation of the IMF upstream assistance to support implementation of revenue administration reforms is normally subject to regular evaluation of progress achieved and assessment of authorities' commitment.

${ }^{23}$ This includes merging direct and indirect tax administration, and transferring all tax collection responsibilities from the treasury to the tax administration.
} 
developments have been noted in a few cases (especially regarding VAT operations), this is an area where significant work is still needed in almost all the countries surveyed for both tax and customs administration.

\section{Conclusions}

On the basis of the preceding sections, it is possible to draw some conclusions about the progress of revenue administration reform in the Middle East. These conclusions are based not only on the information provided in the appendices but also on information gained from a review of IMF TA to selected Middle Eastern countries over the past ten years and from interviews with IMF staff.

The following issues are clearly relevant:

$\checkmark$ Although Middle Eastern countries have been and remain relatively poor performers in terms of tax revenues as a percentage of GDP, there are signs that, with the advent of tax policy changes such as the introduction of the VAT, this performance is improving.

$\checkmark$ Revenues from trade taxes continue to play a strong role in Middle Eastern countries despite world wide reductions in tariff rates and the impact of regional trade agreements.

$\checkmark$ The existence of oil-related state revenues is and will continue to be a determinant in the political imperative to reform tax and trade regimes in that it may limit pressure on several governments to take reform initiatives.

$\checkmark$ On the other hand, the desire to improve and sustain economic growth in non-petroleum sectors will increasingly drive the need for a sound tax system and tax administration.

$\checkmark$ For tax regimes to be effective, the culture and societal attitudes of Middle Eastern countries toward the concept of state taxation need to continue its fundamental shift toward acceptance of the need for taxes, based on a regime of voluntary compliance.

In any assessment of progress in tax and customs administration reform, the above factors are paramount. It is obvious that they will have a profound influence on the extent to which government reform initiatives will be successfully implemented in the coming years. 


\section{Features of Tax Administration in Selected Middle Eastern Countries}

A definition of the tax administration features and the terms used to assess the specific situation in the table below are as follows:

1. Reform strategy. This refers to whether or not there is a formal strategy in place for tax administration reform. An IMF-recommended reform strategy typically includes specific recommendations and a high-level timetable for their implementation, success criteria, and proposals for effective management of the strategy, including governance and project management principles. The comment "plan" refers to situations where a reform strategy has been recommended but implementation is at the early stages only.

2. $\boldsymbol{V A T}$. This refers simply to the existence of a VAT, or plans for one, and does not deal with the nature and performance of the particular VAT.

3. Self-assessment. This refers to the existence of full self-assessment for tax administration. A comment that says "LTO" implies there is self-assessment in the LTO. "VAT" means there is no self-assessment for income tax, but only for VAT.

4. Function-based organization. This refers to whether the tax organization(s) is (are) based on functions (registration, returns processing, audit, etc.).

5. Integrated direct and indirect tax administration. This refers to whether or not direct and indirect tax administrations are integrated, primarily VAT and income tax.

6. LTO. This refers to the existence, or absence, of a dedicated organization to serve large taxpayers.

7. Segmentation. This refers to whether or not the tax administration has undertaken, or plans to undertake, services to specific taxpayer groups other than the largest taxpayers (e.g., medium and small taxpayers).

8. TIN. This refers to the existence, or not, of a unique taxpayer identification number, (TIN), controlled by the tax administration and used by all revenue collecting operations.

9. Taxpayer services. This category refers to taxpayer services specifically, and is primarily intended to indicate whether or not there is a trend toward improving these services.

10. Tax operations. This is a general reference to all tax operations (accounting and payment, audit, collection enforcement, appeals, etc). These are areas where FAD usually makes specific recommendations for improvement. Because this covers a broad range of topics, it is difficult to summarize the situation in a single word. However, the intention is to indicate a general starting point, and the extent to which there has or has not been improvement from the early 1990s. 
1. Information technology IT investments have often been a big part of tax administration reform. Where they have been effective they have focused on re-engineering and simplifying business processes, not merely automating existing, inefficient processes. The intention is to categorize IT status in a single word or phrase to capture the starting point and the trend.

Table 6. Features of Tax Administration in Selected Countries, Early 1990s vs. Today:

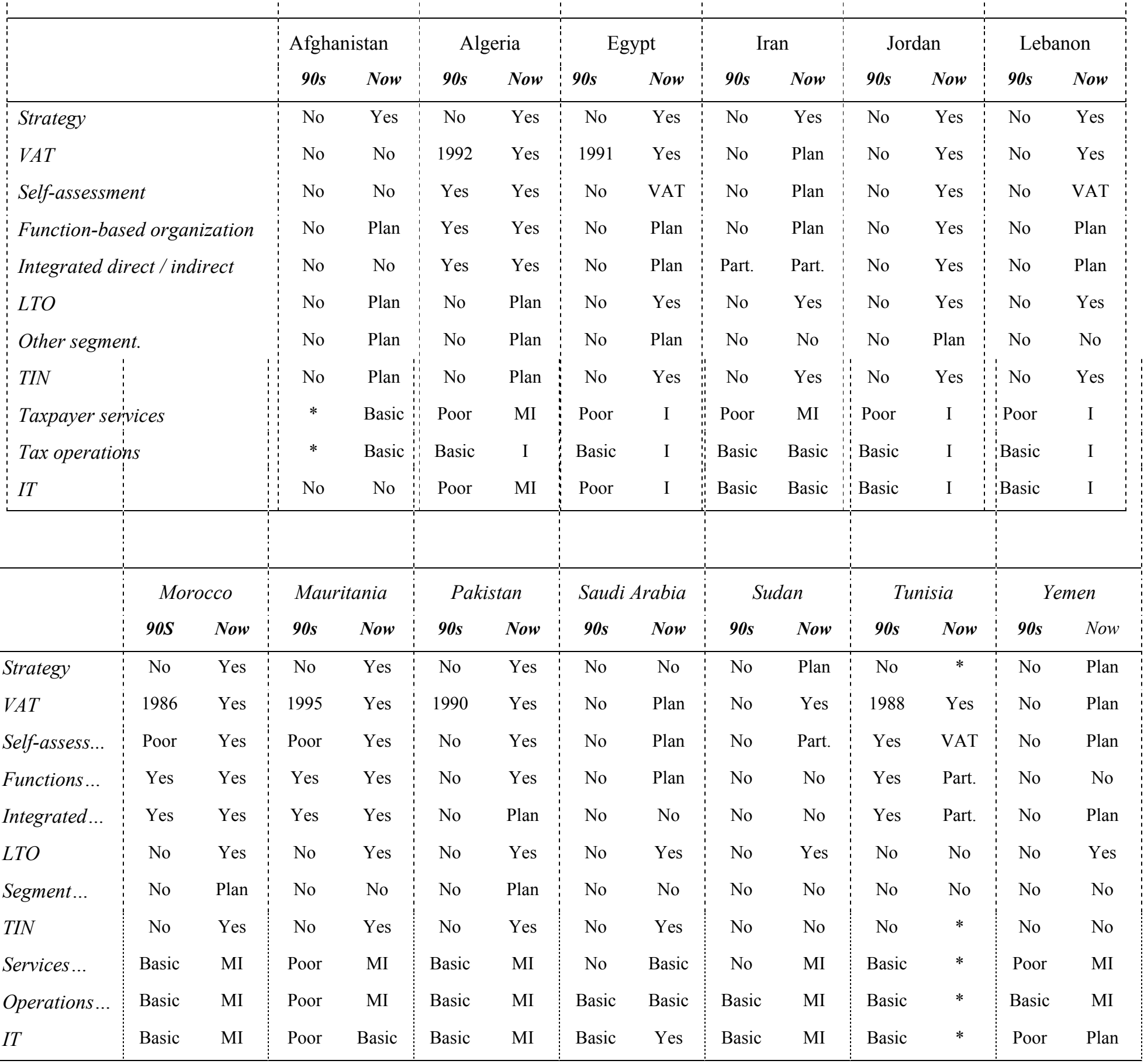

$\mathrm{I}=$ improved; $\mathrm{MI}=$ minor improvements; Part. = partially; * = status not known. 


\section{Features of Customs Administration in Selected Middle Eastern Countries}

A definition of the customs administration features and the terms used to assess the specific situation of each country in the table below are as follows:

1. Reform strategy. This refers to whether or not there is a formal strategy in place for customs administration reform. An IMF-recommended reform strategy typically includes specific recommendations and a high-level timetable for their implementation, success criteria, and proposals for effective management of the strategy, including governance and project management principles. The comment "plan" refers to situations where a reform strategy has been recommended but implementation is at the early stages only.

2. Customs law. This refers to the legislation that governs customs operations and often the organization of the customs function in the government. The term "adequate" means there are or were no major problems with the legislation at a point in time; "needs revision" means the IMF and others have recommended revisions to the legislation, to modernize and/or to reflect new trade arrangements such as the WTO agreements.

3. Customs procedures. Where customs procedures are or were characterized by repetitive checking, unnecessary complexities, a lack of transparency, etc. status is shown as "overly complex" or if slightly better than that, "basic". The term "improved" indicates recognition of problems and implementation of a number of specific actions to make progress (for example, the single administrative document). "Minor improvements" signifies a start in the right direction only.

4. Post-release verification. This category refers to the existence or not of risk-based controls exercised after goods have been cleared for entry, with a de-emphasis of non risk-based physical inspection at point of entry.

5. Effective organization. This refers to whether or not the customs administration has organizational structures and institutional processes that are conducive to integrity and effectiveness in customs administration.

6. Information technology. IT investments are an important part of modern customs administration. A number of customs application software systems have been acquired by developing countries. Where they have been effective they have been adapted to reengineered and simplified business processes, and they have avoided the automation of outdated and often inefficient processes. The intention is to categorize IT status in a single word or phrase to capture the starting point and the trend. 


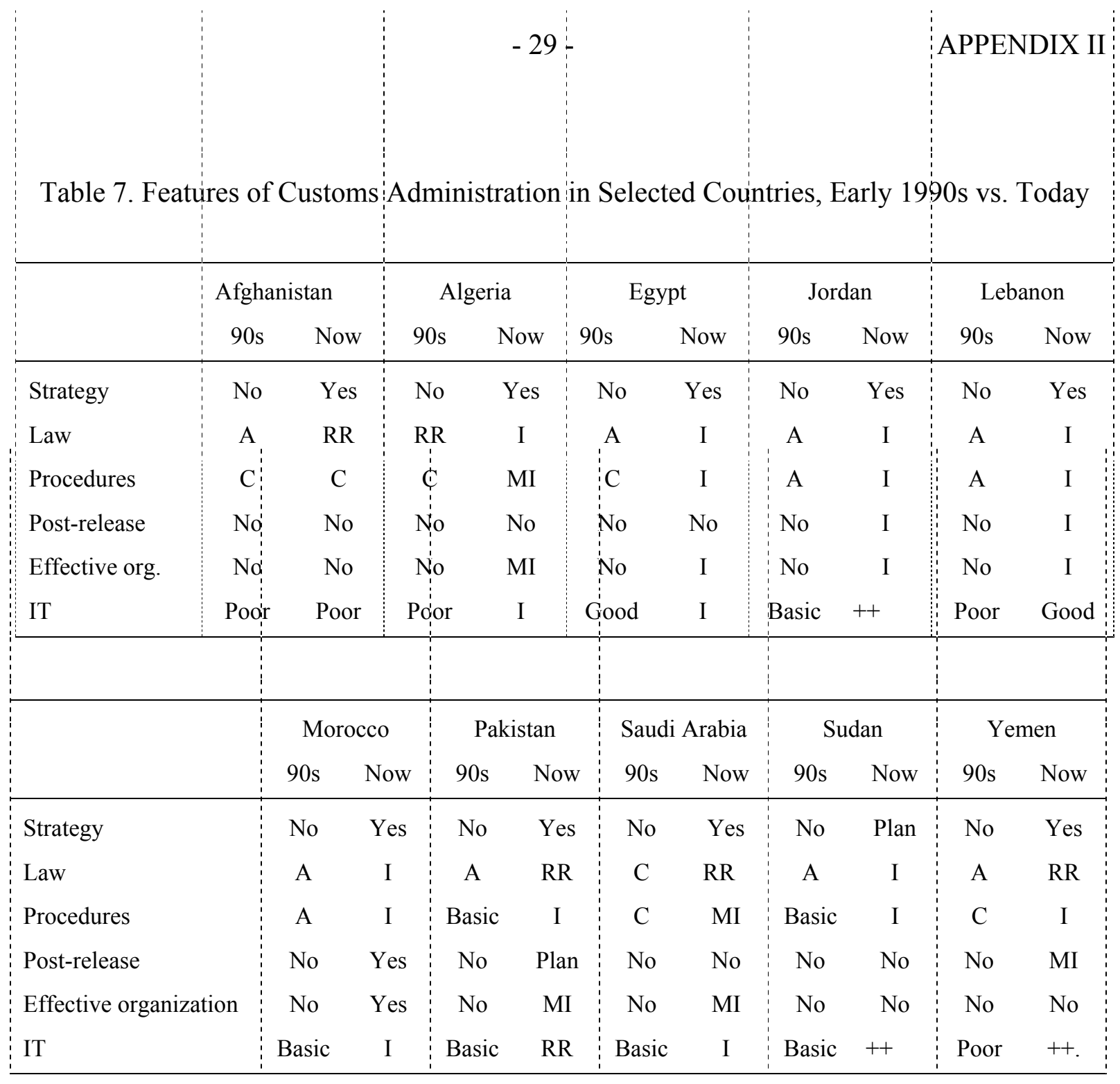

$$
\begin{aligned}
& \mathrm{A}=\text { adequate } \\
& \mathrm{C}=\text { overly complex } \\
& \mathrm{I}=\text { improved } \\
& \mathrm{MI}=\text { minor improvements } \\
& \mathrm{RR}=\text { revision or review required } \\
& ++=\text { ASYCUDA }
\end{aligned}
$$




\section{SeleCted Case StUdies}

\section{EGYPT - Tax and Customs Administration}

\section{Background}

While Egypt has benefited in recent years from an upswing in global economic growth, the fiscal deficit has widened and a decline in revenue is a contributing factor. Implementation of reforms has been slow and incomplete, downward pressures on revenue remain significant and the tax system still has important weaknesses. There has recently been a firm and renewed commitment to reform of tax and customs administration. Revenue administration remains fragmented between an income tax department (ITD), a sales tax department (STD) and a customs department. Integration of the tax departments is an important feature of the new strategy for reform, beginning with the creation of an integrated LTO. The existing reform strategy for customs has been revitalized.

Table 8. Egypt: Consolidated Revenue Collection, 2001/02-2004/05

(In percent of GDP)

\begin{tabular}{ccccc}
\hline & $2001 / 02$ & $2002 / 03$ & $2003 / 04$ & $2004 / 05^{24}$ \\
\hline Central government revenue & 18.8 & 19.1 & 19.1 & 19.7 \\
Tax revenue & 13.7 & 13.9 & 13.7 & 14.1 \\
Taxes on income & 5.8 & 5.6 & 5.7 & 5.6 \\
Corporate income tax & 3.9 & 3.3 & 3.4 & 3.4 \\
Personal income tax & 1.9 & 2.3 & 2.3 & 2.2 \\
Taxes on goods/services & 5.4 & 5.5 & 5.4 & 5.6 \\
Customs duties & 2.5 & 2.7 & 2.5 & 2.9 \\
\hline
\end{tabular}

Source: IMF compilation.

\section{Technical assistance}

The IMF-FAD has provided upstream TA on customs administration in 2002-03. Following the appointment of a new minister of finance in 2004, the reform effort has been expanded to include also tax administration, with a full revenue administration mission undertaken in December 2004. That mission's recommendations now serve as the underpinning of the emerging reform strategy, and FAD has approved a series of visits of a senior advisor to assist the authorities in implementing their reform strategy.

The USAID has provided funding for tax administration reform in the past and is currently actively engaged in customs administration reform. Both the USAID and the European

\footnotetext{
${ }^{24}$ Projected.
} 
Commission have indicated a strong interest in providing long-term TA to support the revenue administration reform that is being developed with FAD assistance.

\section{Tax policy issues}

Over the course of recent years, Egypt has received a number of tax policy missions and has been provided with advice on the implementation of the General Sales Tax (GST) as well as the drafting of new income tax legislation adopted in the spring of 2005. Advice has also been offered on tariff reform. A tax policy mission is set for May 2005 and will look specifically at the GST and provide advice to improve its functioning. At the same time, the mission will consider options for a presumptive tax regime for small taxpayers in Egypt.

\section{Status of tax administration reform and modernization}

The modernization strategy is based on six components: (1) an adequate tax policy framework; (2) simple legislation and procedures; (3) a full regime of self-assessment for large and medium-size taxpayers; (4) function-based organization structures and modern business processes; (5) integration of domestic tax administration; and (6) a strong focus on taxpayer segmentation, beginning with large taxpayers.

$\checkmark$ Reform strategy-Egypt has launched its reform strategy, with the creation of the LTO as a first priority followed quickly by preparation for self-assessment.

$\checkmark$ VAT - the GST law has been in place for ten years and a FAD review of the administrative and policy aspect of the GST is planned. Many recommendations made by previous FAD missions have not been acted upon, including an increase to the threshold.

$\checkmark$ Self-assessment-self-assessment exists for GST and with the passage of the new income tax legislation, will be extended to income tax.

$\checkmark$ Integrated, function-based organization - integration of the ITD and STD is being considered. As a first step, an integrated, function-based LTO is being established.

$\checkmark$ LTO_launch of LTO operations is planned for September 2005.

$\checkmark$ Other segmentation-some initial steps have been taken by the STD by opening one office for medium-size taxpayers, but a plan for full segmentation for both income tax and GST remains to be developed.

$\checkmark$ TIN-a common TIN has been implemented for income tax, GST, and customs.

$\checkmark$ Taxpayer services - positive steps have been taken for the GST, but significant progress is still needed for the income tax.

$\checkmark$ Tax operations-given the more recent introduction of the GST, STD operations are generally stronger in many respects than those of the ITD. 
$\checkmark$ Information technology - the STD has relatively sophisticated IT applications while the presence of IT within the ITD is minimal.

\section{Status of customs reform and modernization}

Reform of the customs administration has been implemented with significant USAID support based on a strategy developed with FAD assistance in 2002. The key components of the strategy include: (1) development of a new law and procedures; (2) implementation of risk management; and (3) closer collaboration with other government agencies.

$\checkmark$ Reform strategy — a formal strategy exists and is actively pursued.

$\checkmark$ Customs law - a new customs law has been drafted and is expected to be tabled in the assembly shortly.

$\checkmark$ Customs procedures - many new procedures have been developed and are being tested at the "model customs center" in Alexandria.

$\checkmark$ Effective organization - the organization structure was re-designed to meet the needs of a modern customs administration.

$\checkmark$ Post assessing-post-release verification is close to non-existent. At a modern Egyptian port, cargo selectivity results in close to one-half of all shipments being referred for inspection (well in excess of international standards).

$\checkmark$ Information technology-IT needs are currently under review as systems do not yet meet the needs of modern customs administration.

\section{Overall assessment of revenue administration reform}

Until recently, the main focus of revenue administration reform in Egypt has been on customs, with insufficient attention paid to reform of tax administration. The introduction of the GST in the early 1990s provided an opportunity to build a modern tax administration, but in the absence of integration, the ITD has lagged significantly behind the STD.

A major revenue administration reform is being implemented by the minister of finance. Resources have been made available to engage professional consultants for the LTO implementation phase. Additional funding will be sought from donors to continue providing the needed expertise for implementation of the full reform program and ensure the necessary knowledge transfer. Strong government support and a commitment to integrate the ITD and STD in the medium term are indicators that the reform strategy is on solid footing. 


\section{JORDAN-Tax and Customs Administration}

\section{Background}

Jordan has decided to modernize its revenue administration by creating an LTO in Amman, establishing a function-based unified tax department headquarters, developing plans for several medium-size taxpayer offices, and developing simplified administrative arrangements for small taxpayers. Revenue administration in Jordan had been organized by tax type, with three departments (customs, income tax, and GST) reporting to the minister of finance. The separate GST department (GSTD) was carved out of customs when the GST was extended to the retail sector in 2001 .

Table 9. Jordan: Consolidated Revenue Collection, 2000-04 (In percent of GDP)

\begin{tabular}{lrrrcc}
\hline & 2000 & 2001 & 2002 & 2003 & 2004 \\
\hline Tax revenue & 16.1 & 16.1 & 14.9 & 15.4 & 18.00 \\
Income tax & 2.7 & 3.1 & 2.9 & 2.8 & 2.7 \\
GST and excises (SST) & 7.8 & 8.1 & 7.6 & 8.5 & 10.4 \\
Customs duties & 4.4 & 3.8 & 3.3 & 3.0 & 3.4 \\
Other taxes & 1.2 & 1.1 & 1.1 & 1.2 & 1.5 \\
\hline
\end{tabular}

Source: IMF staff estimates.

\section{Technical assistance}

Over the past three years, three IMF-FAD TA missions have been provided, including a major review of all revenue administration issues in 2003. Currently, a series of peripatetic assignments of a senior FAD expert is being provided to assist Jordan in implementing its tax administration reforms.

FAD assistance is closely coordinated with the UNDP and France. The UNDP has an ongoing program and funding to support modernization of the income tax department (ITD), particularly computerization. The UNDP continues the support since the decision of the government to integrate domestic tax administration into a unified department. France has also assigned an expert to the tax administration to support the tax administration reforms and implement a comprehensive training strategy.

\section{Status of tax administration reform and modernization}

$\checkmark$ Reform strategy_-Jordan has incorporated the 2003 IMF recommendations into its tax administration reform strategy.

$\checkmark$ VAT - the VAT in Jordan is called the GST. It was established in 1994 and extended to the retail sector in 2001 with IMF assistance. 
$\checkmark$ Self-assessment-self-assessment exists for both income tax and GST. However, further effort is still need to improve tax compliance.

$\checkmark$ Integrated, function-based organization - the existence of separate departments for income tax and GST, reflecting a tax-type orientation, was seen as an impediment to an effective tax administration. Integration, on a functional basis, is now underway.

$\checkmark$ LTO - an LTO has recently been established as a full-service office, covering all taxes.

$\checkmark$ Other segmentation-Jordan has developed a plan for establishment of dedicated offices to serve medium-size taxpayers (i.e., those with an annual turnover above the GST threshold), beginning with implementation of three offices in Amman by end-2006.

$\checkmark$ TIN - separate registration systems and numbers are used for income tax and GST. A unique TIN is being established for all tax and customs purposes.

$\checkmark$ Taxpayer services - efforts have been made, both in the income tax and GST area, to improve services through the creation of pilot centers in Amman to provide a broad range of services (registration, return filing, refunds, objections, clearance certificates).

$\checkmark$ Tax operations - processes for tax operations (enforced collection, audit, returns processing) have been improving for both income tax and GST. Strengthening tax arrears collection and implementing more effective audit programs will be critical for the success of the tax administration reform underway.

$\checkmark$ Information technology - automated systems now exist for both income tax and GST, and efforts have been launched to improve data exchange and possibly re-design systems based on the income tax model.

\section{Status of customs reform and modernization}

$\checkmark$ Reform strategy - a program for customs administration modernization has been underway since 1998 when ASYCUDA was introduced.

$\checkmark$ Customs law - the law allows full implementation of ASYCUDA-based risk profiling.

$\checkmark$ Procedures - automated processes based on ASYCUDA implementation now cover 85 percent of national transactions. Risk-management models have been implemented for inspection activities, based on selection criteria developed by headquarters..

$\checkmark$ Effective organization - improvements are still required to ensure appropriate delegations throughout the organization.

$\checkmark$ Post assessing - a risk management directorate has been established, which includes responsibility for post-release auditing. 
$\checkmark$ Information technology - a fully operational ASYCUDA system has been implemented by Jordanian customs.

\section{Overall assessment of revenue administration reform}

A comprehensive program of reform and modernization is well underway for both tax and customs administration. Integration of domestic tax administration forms the cornerstone of reform, and should eventually provide many benefits to the administration and to taxpayers.

The authorities have made very good use of FAD strategic TA, which has been closely coordinated with the long-term assistance provided by the UNDP and France.

\section{LEBANON-Tax and Customs Administration}

\section{Background}

Significant progress has been made in the 1990s in implementing a customs reform program and the introduction of VAT in February 2002 has been successful. However, important weaknesses remain in the administration of income tax, which if not addressed will severely compromise the implementation of the planned global income tax from 2006.

Table 10. Lebanon: Consolidated Revenue Collection, 2002-04

(In percent of GDP)

\begin{tabular}{lrrr}
\hline & 2002 & 2003 & $2004^{25}$ \\
\hline Total revenue & 22.4 & 24.5 & 23.6 \\
Tax revenue & 15.3 & 16.9 & 16.9 \\
Taxes on income and profits & 2.8 & 3.7 & 3.6 \\
Taxes on property & 1.2 & 1.1 & 1.2 \\
VAT & 3.8 & 4.7 & 4.7 \\
Other direct & 0.7 & 0.6 & 0.6 \\
Taxes on international trade & 6.2 & 6.1 & 6.0 \\
\hline
\end{tabular}

Source: IMF compilation.

\section{Technical assistance}

The IMF-FAD has provided significant TA in recent years, including three revenue administration missions in 2001, 2002, and 2003. These missions have closely coordinated their work with the long-term tax policy and administration advisors financed by the UNDP

\footnotetext{
${ }^{25}$ Projected.
} 
and Canada. Since end-2004, the METAC has also assigned a peripatetic expert to help establish the LTO.

In spite of large scale assistance since 1998, performance of the various parts of the revenue administration and the pace of reforms remains inconsistent, mainly due to significant difficulties in adopting the necessary laws (including the VAT administration act, the tax procedure code, and the income tax law).

\section{Tax policy issues}

In recent years, FAD has also sent a number of tax policy missions to support VAT implementation and replacement of scheduler taxes with a global income tax (GIT). The latest mission in December 2004 provided advice, among others, on the treatment of small businesses (i.e., sole proprietorships with an annual turnover below the VAT threshold), which are not covered by the VAT, and a simplified regime may need to be considered.

\section{Status of tax administration reform and modernization}

FAD has recommended a modernization strategy based on four main components: (1) completion of existing initiatives, including the tax registration and deductions at source programs; (2) establishment of an LTO; (3) creation of a unified, function-based tax administration; and (4) development of an implementation plan for the GIT. A substantial legislation program, including a tax administration law, a tax procedure code, and a GIT law will need to accompany this program

$\checkmark$ Reform strategy_Lebanon has made significant strides in developing a strategic plan for reform, and has articulated the major elements of its strategy.

$\checkmark$ VAT - the VAT was implemented in 2002. While there remain some serious issues in VAT administration (in particular adopting the organizational law), implementation has generally been successful and methods introduced with the VAT are serving as models for other areas of revenue administration.

$\checkmark$ Self-assessment - self-assessment exists for VAT, but needs to be extended to income tax, especially with the planned move to a global income tax.

$\checkmark$ Integrated, function-based organization - the existence of separate departments, reflecting a tax-type orientation, constitutes an impediment to an effective and efficient tax administration in Lebanon. This is clearly the case for the VAT and the income taxes, where the current organization results in duplication, lack of coordination, and inefficient allocation of resources.

$\checkmark$ LTO - preparations for establishment of a LTO began in end-2004 with TA from the METAC. The LTO was implemented as a full-service office, covering all tax types, in May 2005. 
$\checkmark$ Other segmentation —-Lebanon has begun assessing a specific regime for smaller taxpayers, especially in the context of GIT deliberations.

$\checkmark$ TIN—a unified taxpayer identification number has been implemented successfully.

$\checkmark$ Taxpayer services - there have been many improved services to taxpayers as a result of the introduction of VAT, but these have yet to spill over to income tax administration.

$\checkmark$ Tax operations - again, processes for tax operations (enforced collection, audit, returns processing) are seen as particularly strong for VAT. However, for other taxes, there is still room for significant improvement.

$\checkmark$ Information technology - the ministry of finance has acquired the SIGTAS system for tax administration. The VAT makes full use of this system, as will the deductions at source system. Income tax administration lags behind, and does not make full use of the computer system.

\section{Status of customs reform and modernization}

A program for customs administration modernization was embarked upon as early as 1996, based on principles of self-assessment.

$\checkmark$ Reform strategy — a formal reform strategy has been implemented.

$\checkmark$ Customs law - a new customs law was enacted to support customs modernization and WTO accession. Further legislative amendments have been drafted to support the modernization of compliance measures.

$\checkmark$ Customs procedures - pre-release procedures are in line with international standards, but post-release procedures (and attendant legislation) are still under development.

$\checkmark$ Effective organization - improvements are still required to ensure appropriate delegations throughout the organization.

Post assessing - post-release unit has been established and staff trained. Improvements are still needed with respect to penalties, and appropriate delegation of authorities.

$\checkmark$ Information technology — a fully operational system exists (NAJM) and is being utilized.

\section{Overall assessment of revenue administration reform}

The successful introduction of VAT in 2002 has contributed to stronger tax revenue performance, and the new VAT administration can provide a sound basis for restructuring overall domestic tax administration. In contrast, the administration of income taxes is poorly organized with an inappropriate mix of staff, ineffective automation, and inefficient business 
processes and work practices. In relation to customs administration, a solid reform plan is well underway. Further improvements in the areas of tax policy and administration will depend on the political situation and the authorities' commitment to tax reform.

\section{MOROCCO-Tax and Customs Administration}

\section{Background}

Morocco's economic performance over the last three years has been favorable. Despite this, there continue to be a number of reasons for concern. Morocco has entered in to two free trade agreements (with the EU and the United States) which will ultimately reduce customs duties and increase reliance on the tax system. Efforts to increase tax revenues have concentrated on direct taxes with some success, while VAT collection has remained relatively static. The VAT legislation is in need of extensive revision to bring it into line with the modern principles of a VAT.

Table 11. Morocco: Consolidated Revenue Collection, 1999-2003

(In percent of nonagricultural GDP)

\begin{tabular}{lrrrrr}
\hline & 1999 & 2000 & 2001 & 2002 & 2003 \\
\hline Tax revenue & 27.0 & 26.4 & 26.0 & 26.3 & 26.0 \\
Direct taxes & 9.1 & 8.8 & 8.7 & 9.1 & 9.5 \\
VAT & 6.9 & 7.0 & 7.1 & 7.2 & 7.4 \\
Consumption taxes & 5.4 & 5.0 & 4.9 & 4.8 & 4.5 \\
Customs & 4.3 & 4.2 & 3.8 & 3.7 & 3.0 \\
Other & 1.4 & 1.4 & 1.4 & 1.5 & 1.5 \\
\hline
\end{tabular}

Source: IMF compilation.

\section{Technical assistance}

IMF TA through FAD was centered on tax policy and customs administration through the late 1990s, using TA missions. More recently, missions in 2000 and again in 2004 have focused on tax policy and tax administration. The 2000 mission proposed a reform strategy that included the simplification of the VAT and the modernization of the tax administration. The 2004 mission expanded on broad recommendations for reform of the tax administration.

Morocco has received extensive assistance from France and the EU, largely in the form of training and study trips. More recently, the EU has launched a large initiative in Morocco and will focus on tax policy enhancements, beginning this fall.

\section{Tax policy issues}

The tax system in Morocco can be fairly characterized as highly complex. A VAT with multiple rates, a low threshold and many exemptions all contribute to make the tax an 
ineffective vehicle for the government to raise tax revenue and a complicated tax for both the taxpayer and the tax administration. Issues in direct taxation relate mainly to a number of distortions, which have resulted from almost continuous amendments to the various taxes.

\section{Status of tax administration reform and modernization}

Based on the 2000 mission's recommendations, the tax administration was able to advance on a number or fronts, including: creation of two LTOs in Casablanca and Rabat, and transfer of the tax collection function for VAT and the corporate profit tax from the Treasury to the tax administration. The 2004 mission also made a number of recommendations that are captured in this section of this annex.

$\checkmark$ Reform strategy - the strategy was updated by the 2004 mission, based on a thorough reform of the VAT and a renewed approach to modernization of the administration. Reform of the administration will be based on further strengthening of the LTOs, the extension of this type of organization to administer the tax obligations of small and medium-size enterprises, the complete transfer of the collections function to the tax administration, and modernization of tax operations.

$\checkmark$ VAT - the VAT needs a complete overhaul to ensure that this tax is able to perform as efficiently and neutrally as possible. The current four rates should be reduced to two and ultimately one, with a single threshold.

$\checkmark$ Self-assessment-self-assessment exists in Morocco but is a difficult regime for taxpayers, given complicated forms, and relatively little taxpayer education.

$\checkmark$ Function-based organization - following the 2000 and 2004 missions, integration of the tax collection function within the tax department is underway.

$\checkmark$ LTO - there are two LTOs: Casablanca for a number of years and Rabat more recently. The 2004 mission made recommendations for improved performance of the LTOs.

$\checkmark$ Other segmentation - the 2004 mission proposed the establishment of small and mediumsize taxpayer offices in Casablanca and Rabat.

$\checkmark$ TIN — a plan for implementation of a unified taxpayer identification number has been developed, in collaboration with Customs and Treasury.

$\checkmark$ Taxpayer services - activity to date has focused on alerting taxpayers to their obligations using media outlets and the creation of a taxpayer services unit in each regional office.

$\checkmark$ Tax operations - there have been improvements in organization, returns processing and use of the TIN. More improvements are needed in developing processing procedures to reflect self-assessment, establishing a risk-based audit program for income tax, and ensuring proper collection enforcement and a focus on non-filers and non-registrants. 
$\checkmark$ Information technology - the tax administration has completed a comprehensive review and has developed a plan with the assistance of a consulting firm. Development should begin this fall with initial applications available by spring 2005 .

\section{Status of customs reform and modernization}

The customs administration is recognized as leader in reform and modernization efforts. Since 1996, the administration has pursued a reform strategy built around 4 principal objectives: automated review of customs declarations, targeted selection for review, reduced release times and a dialogue with business.

$\checkmark$ Reform strategy — a customs administration reform plan was adopted in 1996.

$\checkmark$ Customs law - in 1999, the customs code had been revised and was scheduled for legislative review. The objective of the revisions was to bring the law in line with the principles of modernization and international trade and to align the penalties and sanctions regime with international standards.

$\checkmark$ Customs procedures - significant enhancements have been made but in 1999, were limited to importers using Casablanca.

$\checkmark$ Post assessing - good progress was made in this area.

$\checkmark$ Information technology - the customs administration has been recognized for its modernization efforts in the area of IT. For example, importers can access SADOC to monitor the progress of the customs clearance for their shipment.

\section{Overall assessment of revenue administration reform}

Revenue collection continues to be constrained by weaknesses in tax administration and policy. From a tax policy perspective, the VAT can no longer be depicted as a neutral and efficient tax, given the number of exemptions and rates that apply. Revenues from the direct tax system (IS and IGR) are likely to plateau and customs duties will continue to drop in light of the free trade agreements with the EU and the United States. From the administrative perspective, the tax and customs administrations have made progress in recent years on a number of fronts (e.g. LTUs), but more remains to be done in a more coherent and deliberate fashion.

\section{PAKISTAN-Tax and Customs Administration}

\section{Background}

Pakistan's recent economic performance has been encouraging — real GDP averaged about 3.5 percent over the last few fiscal years. Notwithstanding this progress, tax revenue collection continues to remain a weak spot. Revenues remain below the level needed to 
finance Pakistan's debt obligations while ensuring needed increases in social expenditures. Improvements to the tax system (policy and administration) remain critical.

Table 12. Pakistan: Federal Revenue Collection, 1999/00-2003/04

(In percent of GDP)

\begin{tabular}{lrrrrr}
\hline & $1999 / 00$ & $2000 / 01$ & $2001 / 02$ & $2002 / 03$ & $2003 / 04$ \\
\hline Tax revenue & 10.7 & 10.6 & 10.4 & 11.0 & 10.5 \\
Income/profit & 3.0 & 3.0 & 3.2 & 3.2 & 3.0 \\
Excise & 1.5 & 1.2 & 1.1 & 0.9 & 0.8 \\
Sales tax & 3.1 & 3.7 & 3.8 & 4.0 & 4.0 \\
Customs & 1.6 & 1.6 & 1.1 & 1.4 & 1.6 \\
Other & 1.5 & 1.1 & 1.2 & 1.5 & 1.1 \\
\hline
\end{tabular}

Source: IMF compilation.

\section{Technical assistance}

IMF TA through FAD has been comprised of a number of TA missions in the 1990s and early 2000s (at least 5 since 1997) and the provision of peripatetic and full time technical advisors (about two FTE over the same time period). The 2001 mission developed elements of a reform strategy including a new agency for tax and customs administration with increased autonomy, establishment of an LTO, income tax structured on a functional basis with integration of income and sales tax operations, extension of self-assessment to all income tax payers, and dedicated taxpayer services and audit functions.

Following the 2001 FAD mission, the World Bank has developed a customs and tax administration reform project (to be supported by a loan agreement). A World Bank consultant has been engaged to assist with detailed planning for the revenue administration reform program, and to prepare required project documentation.

\section{Tax policy issues}

Tax policy issues impacting on tax administration center mainly on the existing GST. This tax continues to suffer from weak design features including complex refund rules and inappropriate input tax credit restrictions.

\section{Status of tax administration reform and modernization}

The need for reform has been recognized by the authorities, and recent measures have included the extension of the GST to services, a re-write of the income tax law, new national tax numbers, improved audit and appeals, and plans for expanded self-assessment. However, in the past, many issues have compromised effective revenue administration such as poor organizational structure, ineffective IT, weak management, and concerns about integrity. 
$\checkmark$ Reform strategy_an initial reform plan was approved by the government in 2001 .

$\checkmark$ VAT - the GST adopted by Pakistan in 1990 was, in principle, a value-added type of tax at the manufacturing and import stages. However, it was problematic at the outset due to a high level of exemptions, fixed taxes for certain industries, inconsistent definitions, complexities regarding input tax credits, and very weak administration. By 1998, a modern, broad-based value-added tax was still lacking because of inadequate policy design and weak administrative processes. Despite some encouraging progress, many of these concerns remain today.

$\checkmark$ Self-assessment - the necessary laws have now been amended and progress in selfassessment for income tax has recently been reported.

$\checkmark$ Function-based organization - it has now been agreed that a longer-term goal will be the full integration of sales and income tax operations.

$\checkmark$ LTO — a large taxpayer unit has been successfully created in Karachi.

$\checkmark$ Other segmentation - a medium taxpayer unit in Lahore intended to be an interim model office for the reorganization of income tax operations, based on functional principles.

$\checkmark$ TIN_a unified taxpayer identification number has been implemented successfully.

$\checkmark$ Taxpayer services - there is active planning for service improvements including design of new income tax returns and a comprehensive education and publicity program.

$\checkmark$ Tax operations - improvements in organization, returns processing, use of banks for payment, and use of the TIN, have been reported. It seems however, that more improvements are needed in developing processing procedures to fully reflect selfassessment, establishing a risk-based audit program for income tax, and ensuring proper collection enforcement and a focus on non-filers and non-registrants.

$\checkmark$ Information technology - a major issue is the need to develop an information systems plan based on long-term business strategy for tax administration.

\section{Status of customs reform and modernization}

The approved customs reform and modernization strategy represents a solid planning framework. Specific plans are now being developed to address outdated legislation, slow and complex procedures, overstaffing and the requirement for better-trained staff. These measures are necessary to reduce inefficiencies and prevent revenue losses through undetected under-valuation, tariff misclassification, and exemption fraud.

$\checkmark$ Reform strategy - a customs administration reform plan was adopted in 2002, augmented by consultant's report January 2003. 
$\checkmark$ Customs law - a full review is required to reflect Kyoto and other requirements.

$\checkmark$ Customs procedures - significant simplification and improvement is required to streamline operations, implement self-assessment, and to provide business requirements for improved systems.

$\checkmark$ Post assessing - a more effective post-release verification and audit program has been included in the reform strategy.

$\checkmark$ Information technology - a gap analysis is required once procedures are rationalized to determine requirements for new IT systems.

\section{Overall assessment of revenue administration reform}

Revenue collection continues to be constrained by a mixture of tax policy design and tax administration issues. From a tax policy design perspective, Pakistan has a low number of income and GST taxpayers relative to its size. Tax exemptions for special interests or particular sectors also undermine the tax system, though the authorities have significantly reduced the number of tax exemptions in recent years and have largely refrained from introducing new exemptions. There is some scope for broadening the GST base by extending it further into the service sector. From the administrative perspective, there is a lack of adequate, computerized data and inefficient resource allocation within the tax administration, which allows many potential taxpayers to escape into the shadow economy. Tax evasion is also fostered by taxpayers' fear of arbitrary and excessive tax assessment, and a lack of resources available for audit and enforcement.

However, revenue administration is being enhanced through the reform initiatives. Moving toward a functional organization that relies on voluntary compliance, self-assessment, riskbased audits, minimal face-to-face contacts between taxpayers and officials, and postassessment reviews in customs, should improve revenue performance.

\section{SUDAN-Tax and Customs Administration}

\section{Background}

The government of Sudan foresees sustained economic growth over the medium term, dependent on progress in implementing a peace agreement. Efforts to strengthen tax revenues are an important part of its current programs. 
Table 13. Sudan: Consolidated Revenue Collection, 2000-04

(In percent of GDP)

\begin{tabular}{crrrrr}
\hline & 2000 & 2001 & 2002 & 2003 & 2004 \\
\hline Total revenue & 11.5 & 11.8 & 13.2 & 16.8 & 21.5 \\
Tax revenue & 5.6 & 6.0 & 6.0 & 6.1 & 8.2 \\
Direct taxes & 1.3 & 1.3 & 1.2 & 1.2 & 1.5 \\
Indirect taxes & 4.2 & 4.7 & 4.8 & 4.9 & 6.7 \\
Customs duties & 2.5 & 2.5 & 2.7 & 2.5 & 3.1 \\
VAT & 0.6 & 1.2 & 1.2 & 1.4 & 1.4 \\
Excise & 1.2 & 1.0 & 0.9 & 1.2 & 2.2 \\
\hline
\end{tabular}

Source: IMF compilation.

\section{Technical assistance}

Sudan has received considerable FAD TA in the revenue administration area. In 1999 and 2000, two missions and six visits by a peripatetic expert were undertaken to assist the authorities in their preparations for a VAT. Following implementation of the VAT on June 1, 2000, three additional peripatetic visits were made to assist with VAT-related issues, and provide limited advice on customs, income tax procedures, and computerization. A mission in September 2003 recommended a strategy for reform of the tax and customs administrations to support the government's objective of increasing non-oil tax revenue.

\section{Tax policy issues}

Administrative improvements alone will not enable the government to meet its revenue objectives and steps have been taken to eliminate widespread tax exemptions. Although improved revenue performance in 2004 have been attributed to a removal of exemptions, further reduction of exemptions is needed.

\section{Status of tax administration reform and modernization}

$\checkmark$ Reform strategy-strategic development of tax administration reform is essentially in the planning stages only.

$\checkmark$ VAT - this is still a relatively new tax in Sudan, but it already accounts for half of the tax department's collections. Moreover, it does so with only 12 percent of resources. VAT administration is considered a model for the other taxes.

$\checkmark$ Self-assessment—only partial self-assessment exists, and self-assessed returns are usually altered by the administration. 
$\checkmark$ Function-based integrated organization - it has been recommended that Sudan move away from the current tax-type organization toward an integrated, function-based organizational structure.

$\checkmark$ LTO-specialist assessment and collection units for the largest business profits taxpayers have been set up. Establishment of a full-service LTO for all tax types was recommended by the 2003 mission report.

$\checkmark$ Other segmentation-function-based district offices for medium taxpayers have been recommended, beginning in Khartoum.

$\checkmark$ TIN-a unified taxpayer identification number has not been implemented yet for all tax types in Sudan.

$\checkmark$ Taxpayer services - there have been improved services to taxpayers because of the introduction of the VAT, and similar taxpayer education efforts have been recommended for the income tax.

$\checkmark$ Tax operations - there have been some improvements in returns processing, registration, and audit. However, much remains to be done including the development of an integrated audit strategy and plan, with particular emphasis on large and high-risk taxpayers.

$\checkmark$ Information technology - a VAT computer system already functions well, and it is being used to develop a basic system for income tax.

\section{Status of customs reform and modernization}

$\checkmark$ Reform strategy - a formal reform strategy needs to be implemented, to build on initiatives to date.

$\checkmark$ Customs law_draft amendments to the 1986 customs law are going through the parliamentary approval process; they are intended to allow for electronic customs declarations and risk-based approaches to examinations and post-clearance audit.

$\checkmark$ Customs procedures - clearance procedures are being re-engineered to take advantage of ASYCUDA ++ features.

$\checkmark$ Effective organization-To date, the organizational structure is not sufficiently modernized to ensure full integrity and effectiveness.

$\checkmark$ Post assessing - post-clearance procedures are not currently used. Development of postclearance audit functions has been recommended.

$\checkmark$ Information technology—98 percent of declarations are now cleared at 11 ASYCUDA ++ sites. The most important issue is to use the ASYCUDA installation as a vehicle for introducing modernized business processes. 


\section{Overall assessment of revenue administration reform}

The successful introduction of VAT in 2000 has contributed to stronger tax revenue performance, and the new VAT administration provides a sound basis for reorganizing overall domestic tax administration. In contrast, the administration of direct taxes is poorly organized with too many staff, too many offices, no automation, and inefficient business processes and work practices. A strong push to remove exemptions, especially on customs duties, also yielded large benefits.

In relation to customs administration, initiatives are underway that will have a significant impact on the future customs administration - negotiations for membership in the WTO; implementation of ASYCUDA ++; and negotiations for the COMESA customs union. These initiatives can be used as the basis for modernizing customs operations to both improve service and increase the effectiveness of revenue collection. 